\title{
The European initiative for quality management in lung cancer care
}

Torsten G. Blum, Anna Rich, David Baldwin, Paul Beckett, Dirk De Ruysscher, Corinne Faivre-Finn, Mina Gaga, Fernando Gamarra, Bogdan Grigoriu, Niels C.G. Hansen, Richard Hubbard, Rudolf Maria Huber, Erik Jakobsen, Dragana Jovanovic, Assia Konsoulova, Jens Kollmeier, Gilbert Massard, John McPhelim, Anne-Pascale Meert, Robert Milroy, Marianne Paesmans, Mick Peake, Paul-Martin Putora, Arnaud Scherpereel, Nicolas Schönfeld, Helmut Sitter, Knut Skaug, Stephen Spiro, Trond-Eirik Strand, Samya Taright, Michael Thomas, Paul E. van Schil, Johan F. Vansteenkiste, Rainer Wiewrodt and Jean-Paul Sculier

Affiliations: For a full list of the authors affiliations see the Acknowledgements section.

Correspondence: Torsten G. Blum, Klinik für Pneumologie, Lungenklinik Heckeshorn, HELIOS Klinikum Emil von Behring, Walterhöeferstr. 11, 14165 Berlin, Germany. E-mail: torsten-gerriet.blumahelios-kliniken.de

ABSTRACT Lung cancer is the commonest cause of cancer-related death worldwide and poses a significant respiratory disease burden. Little is known about the provision of lung cancer care across Europe. The overall aim of the Task Force was to investigate current practice in lung cancer care across Europe.

The Task Force undertook four projects: 1) a narrative literature search on quality management of lung cancer; 2) a survey of national and local infrastructure for lung cancer care in Europe; 3) a benchmarking project on the quality of (inter)national lung cancer guidelines in Europe; and 4) a feasibility study of prospective data collection in a pan-European setting.

There is little peer-reviewed literature on quality management in lung cancer care. The survey revealed important differences in the infrastructure of lung cancer care in Europe. The European guidelines that were assessed displayed wide variation in content and scope, as well as methodological quality but at the same time there was relevant duplication. The feasibility study demonstrated that it is, in principle, feasible to collect prospective demographic and clinical data on patients with lung cancer. Legal obligations vary among countries.

The European Initiative for Quality Management in Lung Cancer Care has provided the first comprehensive snapshot of lung cancer care in Europe.

@ERSpublications

European initiative on quality management in lung cancer: first systematic snapshot on lung cancer care in Europe http://ow.ly/tHfIF

\section{This article has supplementary material available from erj.ersjournals.com}

Received: June 222013 | Accepted after revision: Nov 212013 | First published online: March 232014

Support statement: The European Lung Cancer Audit feasibility study was supported by a grant from Stiftung Oskar Helene Heim (Berlin, Germany).

Conflict of interest: Disclosures can be found alongside the online version of this article at erj.ersjournals.com

Copyright @ERS 2014 


\section{Executive summary}

This European Respiratory Society (ERS) Task Force report describes the first phase of an ambitious initiative with the ultimate aim to improve the quality of care for people with lung cancer across Europe. The Task Force undertook four projects. 1) An extensive review of the literature on quality management revealed evidence that was mainly limited to individual aspects of quality improvement. 2) A baseline survey of national and local infrastructure of healthcare showed marked differences in resources and access to care among 37 countries. 3) A benchmarking project on the quality of guidelines showed that well-resourced guidelines were better. 4) A feasibility study showed that contemporary clinical data collection was possible through a clinical network representing 28 European countries. The Task Force has created a platform for future research and development of initiatives that may lead to improved care for people with lung cancer in Europe.

\section{Introduction}

Lung cancer has one of the worst prognoses of all solid tumours [1]. Globally, there are an estimated 1.4 million deaths each year which represents $18.4 \%$ of cancer deaths [2]. Whilst prevention, diagnosis and treatment of this devastating disease are major challenges, it is also important to identify and address inequalities in care that may account for differences in outcome. Only limited data are available that compare aspects of quality of care for people with lung cancer. These comparisons are usually outcome focused rather than looking at infrastructure or processes, and only involve a limited number of European countries. The latest series of reports from EUROCARE (European Cancer Registry) have looked at survival and resection rates recorded by cancer registries in 25 countries, and have shown potentially important variation, although the completeness of data may be a factor contributing to the differences $[3,4]$. Recently the international benchmarking project, where data quality is thought to be comparable, has shown marked differences in mortality between four European countries with respect to four cancers, including lung [5]. However, valid information on structure, process and resultant quality for each national cancer care network is, for the most part, still lacking.

The European Initiative for Quality Management in Lung Cancer Care (EIQMLCC) was proposed in 2009 by the ERS Thoracic Oncology Assembly in the context of the ERS action plan for thoracic oncology. The aim of the initiative was to sustainably improve the quality of care that people with lung cancer receive through a phased approach. The three proposals of the Thoracic Oncology Assembly were to evaluate the provision of lung cancer care across Europe, to survey the resources available, and to establish a platform of lung cancer physicians upon which to promote region-specific improvements in lung cancer care [6]. The first phase was the focus of an ERS Task Force that ran for a 2-year period from October 2010 to September 2012.

The EIQMLCC contributors are a group of academics and clinicians with broad representation from a large number of European countries. This network was used to collect key data on aspects of the previously unclear European healthcare landscape in relation to lung cancer care. After background research, including methodological considerations of research into quality management [7], as well as further development of the network, including establishing a detailed list of professional and other organisations (see supplementary material), four separate projects were undertaken to evaluate factors that might be expected to influence lung cancer care across Europe: 1) an evaluation of the literature on quality management of lung cancer; 2) a survey of national and local infrastructure for lung cancer care in Europe; 3) a benchmarking project on the quality of (inter)national lung cancer guidelines in Europe; and 4) a feasibility study on prospective data collection on patients in each of the participating countries for a defined period.

These projects represent the methods selected by the Task Force to examine some key elements of quality of care. This Task Force report consists of the methodology, results and summary of each of the four projects. Included in the discussion are proposals for future research and development of this important initiative.

A substantial proportion of the findings are available online; including a short description of the basic epidemiology of lung cancer in Europe (Appendix 1) [8-14], a description of the professional organisations relevant to lung cancer care in Europe (Appendix 2). In addition other appendices are referred to throughout the article.

\section{Task Force quality management projects \\ Narrative literature review \\ Methods}

A narrative literature search on the subject of quality management in lung cancer care was performed. The full search strategy is available online in Appendix 3. The scope of the literature search was developed using the Population, Intervention, Comparison, Outcome (PICO) model during a Task Force meeting. The PICO model is presented in table 1. 
The PICO questions were translated into separate PubMed search strategies and searches performed in July 2011 and updated in November 2012. One reviewer (T. Blum) identified relevant publications from reviewing the abstracts, and excluded those that were out of scope using the search questions (Appendix 4 in supplementary material). Articles were reported according to the PRISMA (Preferred Reporting Items for Systematic Reviews and Meta-Analysis) system [15]. Articles were then graded using criteria described by the Oxford Centre for Evidence-based Medicine [16].

Papers were classified into five groups (Appendix 5 in supplementary material): 1) referral practice and waiting times; 2) structure and process; 3) volume of activity; 4) inequalities in lung cancer care; and 5) quality assurance (cancer registries, quality assurance and outcome, and quality indicators).

\section{Results}

A total of 33561 references were screened and 1547 were allocated to the five main groups (fig. 1). 289 articles were duplicates leaving 1258 for further evaluation. Study design and methodology were heterogeneous and, therefore, meta-analyses were not feasible. Most studies were conducted at a local or regional level and most were single centre studies. One meta-analysis, on volume of surgical activity, was the only high-level evidence on quality management in lung cancer [17] and no papers were identified that dealt with a comprehensive quality management system. Studies often examined only single process steps of the lung cancer care pathway.

\section{Referral practice and waiting times}

113 publications were evaluated that examined a variety of steps in the care pathway. Studies were largely descriptive and based at institutional, regional or national level. They described specific reasons for the delays such as referral barriers, organisational problems or limited resources [18-22]. A few studies examined the value of fast track services that resulted in reduced waiting times [23-26]. Evidence for an effect of waiting times on prognosis was conflicting. YILMAZ et al. [27] reported no negative impact on pathological tumour stage when there was a delay in treatment, whereas O'Rourke and EDWARDS [21] and MOHAMmed et al. [28] described tumour progression and inoperability following delays in starting treatment. A systematic review from Olsson et al. [29], which reviewed 53 papers, found there was no clear evidence that a timely diagnostic pathway resulted in improved survival.

\section{Structure and process}

158 articles were evaluated. The added value of lung cancer centres was examined in some studies but there was no common definition for a lung cancer centre. These institutions were generally characterised by a

TABLE 1 The Population, Intervention, Comparison, Outcome definitions

\begin{tabular}{|c|c|c|c|}
\hline Population & Intervention & Comparison & Outcome \\
\hline Lung cancer & $\begin{array}{l}\text { Referral } \\
\text { Diagnostics } \\
\text { Therapy } \\
\text { Surgery } \\
\text { Systemic therapy } \\
\text { Radiotherapy } \\
\text { Radiochemotherapy } \\
\text { Palliative/supportive care } \\
\text { Guidelines } \\
\text { Adherence } \\
\text { Implementation } \\
\text { Quality management } \\
\text { Lung cancer centres } \\
\text { Pathways/fast track } \\
\text { Multidisciplinary team } \\
\text { Quality assurance } \\
\text { Cancer registry } \\
\text { Audit } \\
\text { Survey } \\
\text { Quality indicators } \\
\text { Volumes/minimum quantities } \\
\text { Disparities }\end{array}$ & Other interventions or no intervention & $\begin{array}{l}\text { Mortality } \\
\text { Morbidity/complications } \\
\text { Quality of life } \\
\text { Satisfaction with care } \\
\text { Timeliness/delay }\end{array}$ \\
\hline
\end{tabular}




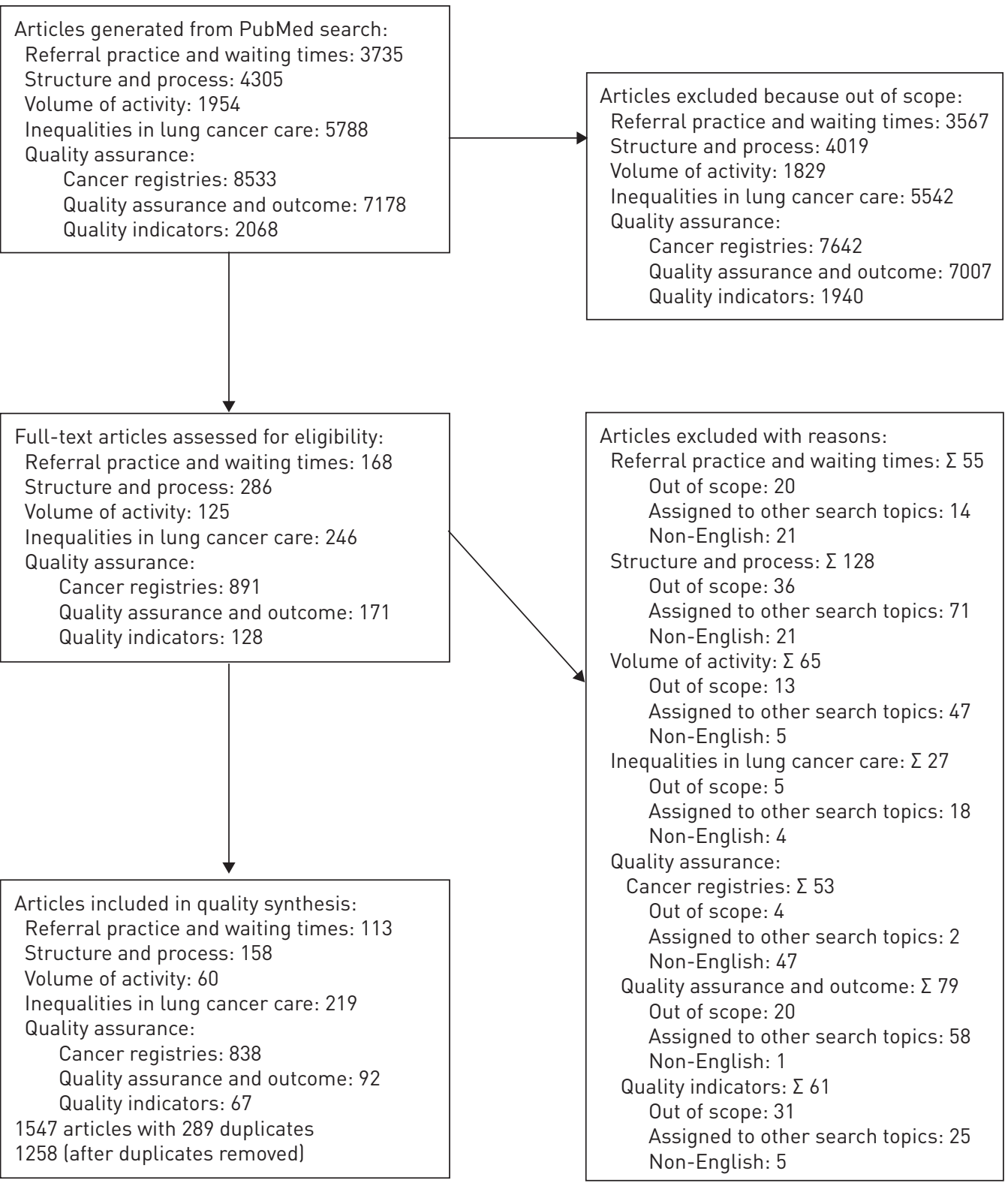

FIGURE 1 Flow diagram illustrating the process of generating articles for literature review. All numbers relate to the number of articles.

co-ordinated, multi-professional, process-oriented approach to lung cancer care. Lung cancer centres seem to have faster diagnostic and therapeutic processes and there was some evidence for better patient and caregivers' satisfaction [30,31]. There were no data to support a significant survival benefit. The majority of studies examined the benefit of multidisciplinary teams (MDT) [30-37]. Coory et al. [34] published a systematic review of MDTs in lung cancer care. However, there was no common definition of the MDT and the purpose, composition and operational factors were variable. Some studies reported a higher rate of adherence to guideline recommendations and a higher number of patients undergoing treatment with curative intent $[38,39]$. Two studies found improved survival after the introduction of MDTs [36, 40].

A number of studies from single centres looked at better access to care, acceleration of diagnostic steps, aspects of thoracic surgery, radiotherapy and integration of palliative care [23, 25, 41-43]. In two independent studies by SAlati et al. [44] and SCHWARZBACH et al. [45], the implementation of a clinical pathway for thoracic surgery led to a reduction of hospital stay without negatively influencing readmission rates. 
AvELING et al. [46] described 30 paired MDTs performing reciprocal peer-review visits, to try and identify elements of good practice and encourage reflective analysis. Whilst the visits were a positive experience, implementation of any improvements required substantial support [46].

Volume of activity

60 studies were identified, the majority of which described the relationship of volume of lung cancer surgery to outcomes. Studies were mainly retrospective and were from both single and multiple centres. There was some evidence for better short-term survival and lower complication rates with higher volume services for institutional or individual surgeons [17, 47-52]. A retrospective Japanese study by YASUNAGA et al. [53] showed a positive correlation between the amount of care-taking staff (physicians and nurses) and shortterm survival in patients undergoing lung cancer surgery. One study showed a relationship between higher volume chemo-radiotherapy services and better outcomes [54].

Inequalities in lung cancer care

219 publications were evaluated that reported variation in aspects of care that may influence survival. For England and Wales, the National Lung Cancer Audit has shown significant regional inequalities in resection rates and other active treatment rates [55-57]. Several Norwegian studies have shown regional variations in resection rates and risk factors for post-operative mortality, as well as in the radiotherapy and chemotherapy regimens used [58-61].

Quality assurance

997 studies were identified. The majority (84\%) described results from regional or national lung cancer registries. These studies measured demographic, clinical and outcome data (most often on survival) whereas others addressed quality of life, burden of symptoms and timing of care as recently reviewed by DE GEER et al. [62]. In addition, several surveys and audits at the regional and national level have described different aspects of care and made recommendations for improvement in referral practices, and diagnostic and therapeutic pathways. These can then be evaluated as part of a quality assurance programme to assess impact on outcome measures such as survival $[63,64]$.

For Denmark, the Netherlands and Germany, the process of the development of national quality indicator sets for lung cancer care, as well as their evaluation, were described providing valuable information on the reference intervals of these tools [65-67]. Two recent review articles by LENNES et al. [68] and TANVETYANON [69] describe quality indicator systems for lung cancer care.

\section{Summary}

An extensive search for research evidence and other literature on quality management in lung cancer revealed that there was little high-grade evidence and no published work on projects as ambitious as EIQMLCC. Studies were predominantly performed at institutional or regional levels, primarily addressing single facets of the lung cancer care pathway. The design of studies was highly variable making comparisons difficult, they were often retrospective and many had small numbers. The benefit of MDTs, fast track clinics and lung cancer centres was described. The National Lung Cancer Audit project in the UK and some studies in Norway have looked at national variations in care. Several studies dealt with methods of quality assurance of lung cancer care including the utilisation of quality indicator systems that might be useful in future panEuropean quality improvement programmes.

\section{Survey of national and local infrastructure and key elements of care}

One of the key factors identified by the Task Force as fundamental to the provision of high-quality care in lung cancer is healthcare infrastructure. This is heavily influenced by what makes countries unique; their historical, cultural, political, geographical and socioeconomic characteristics. Therefore, one of the main objectives was to document the healthcare infrastructure across Europe to enable an assessment of how this might impact on lung cancer care.

\section{Methods}

In order to gather information on healthcare infrastructure across Europe, national representatives were sought. They were identified in three stages, resulting in representation from 37 European countries. 1) The national delegates of the ERS were contacted and asked to provide details of a clinician with a special interest in lung cancer care in their country $(n=40)$. 2) The Thoracic Oncology Assembly contact database was used $(\mathrm{n}=344)$. 3) A request was made via personal contacts of any of the Task Force members to obtain representation from countries not otherwise represented after stages 1 and 2 . 
National infrastructure survey

A novel questionnaire was designed by the Task Force (based on expert opinion) to determine the ease of access to care and what care was provided by which clinician according to specialisation (Appendix 6 in supplementary material). Questions were also asked about the availability of national guidelines, the use of the Union for International Cancer Control staging system and whether data collection was routinely undertaken. Questionnaires were sent to the national representatives identified from 37 countries, of whom 23 were respiratory physicians, 10 were oncologists, one was accredited in both respiratory medicine and oncology, and three were thoracic surgeons.

The questionnaire was sent out in February 2011, and the preliminary results were discussed by the Task Force in May 2011. The national survey results were summarised and returned to participants who were asked to check and confirm submitted data in March 2012. Final results were analysed qualitatively using the thematic approach outlined by BRAUN and Clarke [70].

Local survey of infrastructure and key elements of care

The results from the national survey, as well as a survey of Heads of lung cancer MDTs in England previously employed by National Institute for Health and Care Excellence [71], were used to design a second survey to investigate in more detail the provision of lung cancer care at a local level, i.e. within hospitals and their catchment area. This survey was created by P. Beckett and was only available online. All the national representatives identified via the national questionnaire were asked to encourage colleagues within their country and other countries to complete the online survey (Appendix 7 in supplementary material). The results were analysed using Stata (version 11; Stata Corp., College Station, TX, USA).

Results

National infrastructure survey

All national representatives from the 37 countries responded to our request for information. The majority of the surveys were complete, but the section concerning the cost of several elements of the patient pathway, such as investigations and an overnight stay in hospital, were often incomplete.

\section{Healthcare infrastructure}

25 of the 37 responders indicated that their countries fund the healthcare system through a form of national health service, based on income tax contributions or a mandatory national health insurance programme. In these countries, an individual does not pay at the time of consultation with a primary care physician as the fee is covered by the national or state health service or insurance programme. In Germany, Sweden and Norway, an individual pays a nominal fee for a consultation with health professionals at both primary and secondary care up to an annual limit, at which point all further contact with health professionals is free. In France, Luxembourg and Belgium, an individual pays a proportion of the fee for an appointment. The remainder is claimed back from social security or covered by compulsory public health insurance and longterm care insurance. In Ireland there are several different ways in which healthcare is funded. Approximately half the population have voluntary private health insurance and a further $35 \%$ are entitled to a "medical card". This entitles them to free healthcare and is provided to all individuals with a chronic health condition, those who are unfit to work, those on a low income or unemployed and those aged $>70$ years. The remaining 15\% may be entitled to a medical card but choose to keep private health insurance as well.

Most surveyed countries have a sector of the health service that is privately funded and patients can choose to pay to reduce delays. In 14 countries this was thought to be relevant to lung cancer care. A further 18 countries felt that private physicians were not relevant to the care required by patients with lung cancer. In four countries there did not appear to be any private health care, these were: Belarus, Kyrgyzstan, Luxembourg and Slovenia.

Access to healthcare

In all surveyed European countries, a patient can present themselves to secondary care in an emergency. In 14 countries individuals can refer themselves directly to secondary care and often they can choose which hospital and which doctor they see. However, in the vast majority of countries the usual route of referral to secondary care is via the primary care physician. Exceptions to this are Greece and Cyprus where there is no universal coverage by primary care physicians. Therefore, individuals in these countries can either choose to pay and see a physician privately or refer themselves to secondary care. Payment is not required at secondary care for patients who have cancer, cardiac and renal disease. In Bulgaria there is a limit on the number of referrals a primary care physician can make to a secondary care specialist each month. This introduces a delay in the lung cancer pathway. 
Provision of healthcare

Lung cancer treatment in Europe is provided by physicians from different specialties (table 2). The exception is radiotherapy, which is universally delivered by radiotherapists (clinical oncologists in the UK). The majority of chemotherapy is provided by oncologists in almost half (18 out of 37) of the countries surveyed, and by oncologists and respiratory physicians in equal measure in eight countries. In the remaining third (11 out of 37), respiratory physicians provide chemotherapy. Lung cancer surgery is predominantly provided by thoracic surgeons in 26 countries. However, in several countries cardiothoracic surgeons are the main providers, either alone (seven out of 37 ) or alongside pure thoracic surgeons (one out of 37). In Italy and the Netherlands, general surgeons are involved in lung cancer surgery alongside thoracic and cardiothoracic surgeons. In Belgium, thoracic and cardiothoracic surgery are not separate entities, but fall within general surgery. The exact specialty of physicians providing palliative care to patients with lung cancer was very varied. Palliative care physicians were reported in 13 European countries, but this was often alongside colleagues from respiratory medicine, oncology and primary care.

Staging

The seventh version of the Union for International Cancer Control staging system is used universally in almost all countries surveyed. The exceptions are: Slovakia, where this version has not been translated into Slovak; and Romania, Serbia and Bosnia-Herzegovina where its use is not universal (at date of

\section{TABLE 2 Professionals providing the majority of specific modalities of lung cancer care by country}

\begin{tabular}{|c|c|c|c|c|}
\hline Country & Chemotherapy & Radiotherapy & Surgery & Palliative care \\
\hline Albania & Oncologist & RTx & Thoracic & Palliative care physician \\
\hline Austria & Respiratory physician/oncologist & RTx & Thoracic & $\begin{array}{l}\text { Respiratory physician/oncologist/ } \\
\text { palliative care physician }\end{array}$ \\
\hline Belarus & Oncologist & $\mathrm{RTx}$ & Thoracic & Respiratory physician \\
\hline Belgium & Respiratory physician/oncologist & RTx & $\begin{array}{l}\text { General (cardio/ } \\
\text { cardiothoracic) }\end{array}$ & Oncologist \\
\hline Bosnia-Herzegovina & Respiratory physician & $\mathrm{RTx}$ & Thoracic & $\begin{array}{c}\text { Palliative care physician/respiratory } \\
\text { physician }\end{array}$ \\
\hline Bulgaria & Oncologist & RTx & Thoracic & Oncologist \\
\hline Croatia & Respiratory physician/oncologist & $\mathrm{RTx}$ & Thoracic & Respiratory physician \\
\hline Cyprus & Oncologist & RTx & Cardiothoracic & Oncologist \\
\hline Czech Republic & Respiratory physician & RTx & Thoracic & Respiratory physician \\
\hline Denmark & Oncologist & RTx & Thoracic & Oncologist \\
\hline Estonia & Oncologist & RTx & Thoracic & Respiratory physician \\
\hline Finland & Respiratory physician/oncologist & RTx & Cardiothoracic & Primary Care \\
\hline France & Respiratory physician & RTx & Thoracic & $\begin{array}{l}\text { Respiratory physician/oncologist/ } \\
\text { RTx }\end{array}$ \\
\hline Germany & Respiratory physician & RTx & Thoracic & $\begin{array}{l}\text { Respiratory physician/oncologist/ } \\
\text { palliative care physician }\end{array}$ \\
\hline Greece & Respiratory physician/oncologist & RTx & Thoracic & Respiratory physician \\
\hline Hungary & Respiratory physician & RTx & Thoracic & Respiratory physician \\
\hline Iceland & Oncologist & RTx & Cardiothoracic & Oncologist \\
\hline Ireland & Oncologist & $\mathrm{RTx}$ & Cardiothoracic & Palliative care physician \\
\hline Italy & Oncologist & $\mathrm{RTx}$ & $\begin{array}{l}\text { Thoracic/ } \\
\text { general }\end{array}$ & Oncologist \\
\hline Kyrgyzstan & Oncologist & RTx & Thoracic & Oncologist \\
\hline Lithuania & Respiratory physician & RTx & Thoracic & Primary care \\
\hline Luxembourg & Respiratory physician/oncologist & $\mathrm{RTx}$ & Cardiothoracic & Palliative care physician \\
\hline Malta & Oncologist & RTx & Cardiothoracic & Palliative care physician/oncologist \\
\hline Netherlands & Respiratory physician & $\mathrm{RTx}$ & $\begin{array}{l}\text { Cardiothoracic/ } \\
\text { thoracic/general }\end{array}$ & Primary care \\
\hline Norway & Respiratory physician & $\mathrm{RTx}$ & Cardiothoracic & $\begin{array}{c}\text { Respiratory physician/palliative care } \\
\text { physician }\end{array}$ \\
\hline Poland & Oncologist & RTx & Thoracic & Palliative care physician \\
\hline Portugal & Respiratory physician & RTx & Thoracic & Respiratory physician \\
\hline Romania & Oncologist & $\mathrm{RTx}$ & Thoracic & $\begin{array}{c}\text { Oncologist/respiratory physician/ } \\
\text { palliative care physician }\end{array}$ \\
\hline Serbia & Respiratory physician & RTx & Thoracic & Respiratory physician \\
\hline Slovenia & Respiratory physician/oncologist & RTx & Thoracic & Respiratory physician \\
\hline Slovakia & Oncologist & $\mathrm{RTx}$ & Thoracic & Respiratory physician/oncologist \\
\hline Spain & Oncologist & RTx & Thoracic & Respiratory physician \\
\hline Sweden & Respiratory physician & RTx & Thoracic & Palliative care physician \\
\hline Switzerland & Oncologist & RTx & Thoracic & Palliative care physician \\
\hline Turkey & Respiratory physician/oncologist & RTx & Thoracic & Respiratory physician \\
\hline Ukraine & Oncologist & RTx & Thoracic & Oncologist \\
\hline UK & Oncologist & $\mathrm{RTx}$ & $\begin{array}{l}\text { Thoracic/ } \\
\text { cardiothoracic }\end{array}$ & $\begin{array}{c}\text { Respiratory physician/palliative care } \\
\text { physician }\end{array}$ \\
\hline
\end{tabular}

$\mathrm{RTx}$ : radiation/clinical oncologist. 
questionnaire). The date the latest version of the staging system was adopted ranged between January 2009 and January 2011 (table 3).

\section{Data collection}

The majority of the surveyed European countries collected data on individuals with lung cancer. In 19 countries, national data collection was already established and in 16 of these countries it was via a cancer registry. In the majority of countries with a cancer registry, data were only collected on histologically or cytologically confirmed cases. Two countries (Denmark and the UK) have a national data collection programme that is independent of the cancer registries. France, Germany and Spain have limited data collection at the local level. Albania and Greece do not routinely collect data.

Local survey of infrastructure and key elements of care

There were 350 responses from 38 countries to the online survey of local lung cancer care. These responses came from some countries that did not respond to the national survey (Former Yugoslav Republic of Macedonia and Israel). Instead of the UK as a whole, the component countries, England, Scotland and Wales responded but no representative from Northern Ireland was identified. Three countries who responded to the national survey did not take part in the local survey: Iceland, Kyrgyzstan and the Ukraine. Details of the features of the hospitals and several key indicators of lung cancer care are illustrated in tables 4-7.

Table 4 illustrates the range of different healthcare infrastructures across Europe. In some countries there are no geographical boundaries (catchment areas) for patient access to individual hospitals. In other countries patient choice is limited to their local hospital and in others, whilst patients are allowed to choose which hospital they attend, the majority would choose their local hospital. In 2010, the countries with a median $>400$ new patients per hospital were Albania, Belarus, Bulgaria, the Czech Republic, Poland, Romania and Slovenia. The single respondent from Poland reported 1000 new cases in 2010. In several countries all patients with lung cancer are referred to a single tertiary hospital providing specialist care for the whole country.

Table 5 shows the distance that patients must travel to access thoracic surgery. In 16 countries this was $>100 \mathrm{~km}$. The majority of these countries had longer waiting times for surgery.

Table 6 demonstrates that there is wide variation in histological confirmation rate (HCR), both within and between European countries. Only two hospitals stated their HCR was $<50 \%$, and only 30 hospitals stated their HCR was between $50 \%$ and $75 \%(<10 \%$ of the cohort). A third of respondents stated their HCR was between $75 \%$ and $90 \%$, and this included the majority of participants from England, Italy and Scotland. Almost 50\% reported a HCR of $>90 \%$, including the majority of hospitals in Belgium, Denmark, France and Germany. Of those reporting a HCR $>90 \%$, over one-third (57 (36\%) out of 160) were estimates rather than accurate results.

There was wide variation in the reported surgical resection rate. For some countries a high proportion of participants reported a low resection rate of $5-10 \%$ in their hospital. These were Austria (67\%), England (17\%), Malta (100\%), Republic of Serbia (50\%), Romania (25\%), Slovenia (75\%) and Wales (100\%).

TABLE 3 Adoption of seventh version of the Union for International Cancer Control staging system

\begin{tabular}{ll} 
Start date & Country \\
$\begin{array}{l}\text { January/February 2009 } \\
\text { May 2009 }\end{array}$ & $\begin{array}{l}\text { Denmark, Luxembourg, Norway, Switzerland } \\
\text { Turkey (not universal) }\end{array}$ \\
& $\begin{array}{l}\text { Belgium, Bulgaria, Cyprus, France, Germany, Greece, Hungary, } \\
\text { Netherlands, Poland, Portugal, Slovenia, Sweden, Ukraine, UK }\end{array}$ \\
$\begin{array}{l}\text { March } 2010 \\
\text { May 2010 }\end{array}$ & Serbia \\
June 2010 & Estonia \\
October 2010 & Albania, Austria, Lithuania lexact date unknown), Spain \\
$\mathbf{2 0 1 0 ~ ( m o n t h ~ u n k n o w n ) ~}$ & Bosnia-Herzegovina, Iceland \\
January/February 2011 & Italy, Finland \\
\hline
\end{tabular}

No date was provided for Malta and Kyrgyzstan. 


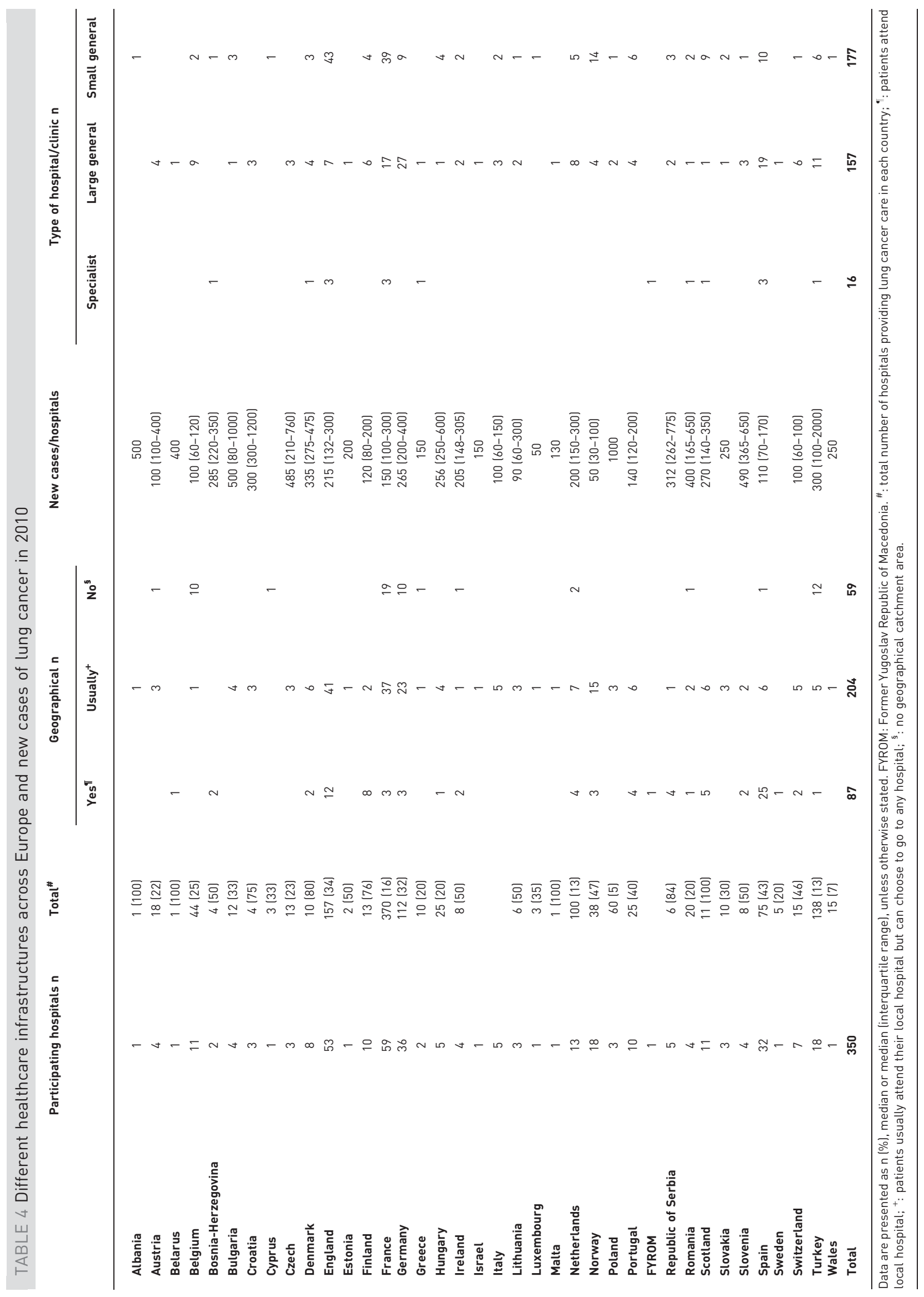




\section{TABLE 5 Distance travelled by patients and waiting times for thoracic surgery}

\begin{tabular}{|c|c|c|c|c|c|c|c|c|c|}
\hline & & & & & & \\
\hline & & & $0^{\#}$ & $<50$ & $50-100$ & $>100$ & $<2$ & $2-4$ & $>4$ \\
\hline Albania & 1 & 1 & & & & & & & \\
\hline Austria & 4 & 1 & 2 & 1 & & & 2 & 1 & \\
\hline Belarus & 1 & & & & & 1 & & & 1 \\
\hline Belgium & 11 & 2 & 5 & 4 & & & 7 & 2 & \\
\hline Bosnia-Herzegovina & 2 & 1 & & & & 1 & & & 1 \\
\hline Bulgaria & 4 & 1 & 2 & & & 1 & & 2 & 1 \\
\hline Croatia & 3 & 1 & 1 & 1 & & & 1 & 1 & \\
\hline Cyprus & 1 & 1 & & & & & & & \\
\hline Czech & 3 & 1 & 1 & 1 & & & 2 & & \\
\hline Denmark & 8 & & 7 & & 1 & & 6 & 1 & 1 \\
\hline England & 53 & 1 & 13 & 32 & 6 & 1 & 50 & 2 & \\
\hline Estonia & 1 & & 1 & & & & & & 1 \\
\hline Finland & 10 & 1 & 5 & & 1 & 3 & 5 & 4 & \\
\hline France & 59 & 6 & 23 & 21 & 5 & 4 & 32 & 20 & 1 \\
\hline Germany & 36 & 7 & 16 & 12 & 1 & & 25 & & 4 \\
\hline Greece & 2 & & & 2 & & & 2 & & \\
\hline Hungary & 5 & 1 & & 3 & & 1 & & 4 & \\
\hline Ireland & 4 & & & 3 & & 1 & 3 & 1 & \\
\hline Israel & 1 & & & 1 & & & 1 & & \\
\hline Italy & 5 & & 3 & 1 & 1 & & 2 & 3 & \\
\hline Lithuania & 3 & 2 & & & & 1 & & & 1 \\
\hline Luxembourg & 1 & & 1 & & & & 1 & & \\
\hline Malta & 1 & & 1 & & & & 1 & & \\
\hline Netherlands & 13 & 1 & 11 & 1 & & & 11 & 1 & \\
\hline $\begin{array}{l}\text { Norway } \\
\text { Poland }\end{array}$ & $\begin{array}{c}18 \\
3\end{array}$ & $\begin{array}{l}3 \\
2\end{array}$ & 1 & $\begin{array}{l}4 \\
1\end{array}$ & 4 & 6 & 4 & $\begin{array}{l}5 \\
1\end{array}$ & 6 \\
\hline Portugal & 10 & 3 & 3 & 3 & & 1 & 5 & 2 & \\
\hline FYROM & 1 & & & 1 & & & 1 & & \\
\hline Republic of Serbia & 5 & 2 & 1 & & 1 & 1 & & 3 & \\
\hline Romania & 4 & 1 & & 2 & & 1 & 1 & 1 & 1 \\
\hline Scotland & 11 & 2 & 1 & 6 & 1 & 1 & 9 & & \\
\hline Slovakia & 3 & 3 & & & & & & & \\
\hline Slovenia & 4 & 2 & 1 & 1 & & & 1 & 1 & \\
\hline Spain & 32 & 11 & 8 & 5 & 2 & 6 & 11 & 10 & \\
\hline Sweden & 1 & 1 & & & & & & & \\
\hline Switzerland & 7 & 2 & 4 & 1 & & & 5 & & \\
\hline Turkey & 18 & 4 & 11 & 1 & & 2 & 12 & & 2 \\
\hline Wales & 1 & & & 1 & & & & 1 & \\
\hline Total & 350 & 64 & 122 & 109 & 23 & 32 & 200 & 66 & 20 \\
\hline
\end{tabular}

Data are presented as n. FYROM: Former Yugoslav Republic of Macedonia. ${ }^{\#}$ : thoracic surgery was available at the diagnosing hospital.

Table 7 shows the results for the composition of the MDT. Whilst this was as expected for many countries, there are some results that may not reflect the true situation. The concept of the MDT is not the same for all countries: some recognise a team that regularly meets to discuss the management of every patient, whilst others acknowledge the team but do not meet regularly, and others do not have MDTs. In some countries, for example Poland, there is more than one lung cancer MDT working independently within the same hospital, this can give rise to the apparent exaggerated size of the MDT as reported in the local survey.

\section{Summary}

This project has shown that it is feasible to collect data from large numbers of European countries both at a national and local level. The national survey showed that there were many differences in the structure and provision of care, as well as in access to care. In many countries more than one specialty provides chemotherapy, and surgery is provided by surgeons of varying specialisation. The local survey suggested considerable variation in access to diagnostic and treatment modalities, rates of histological confirmation and surgical resection, and usage of MDTs. 


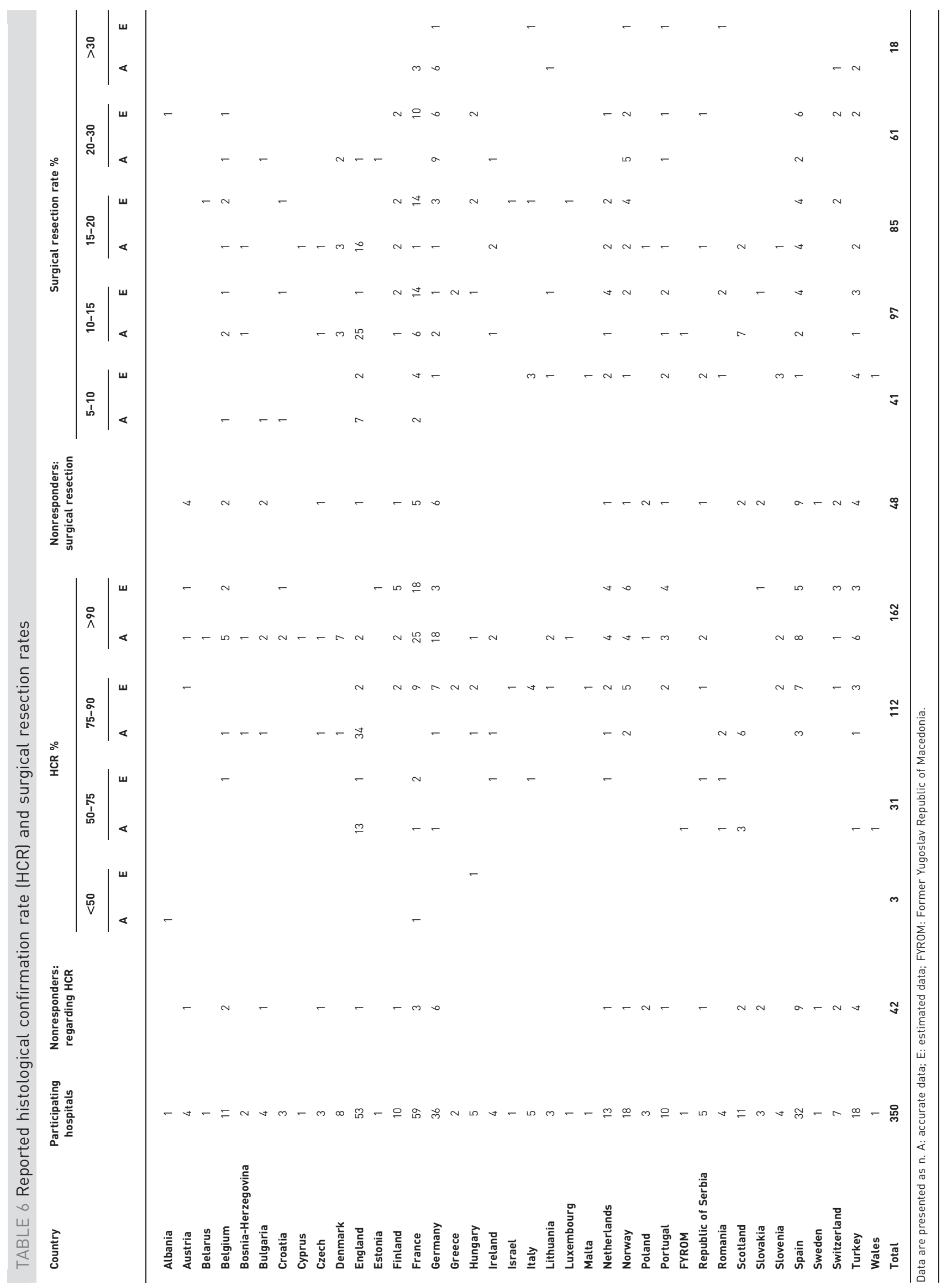




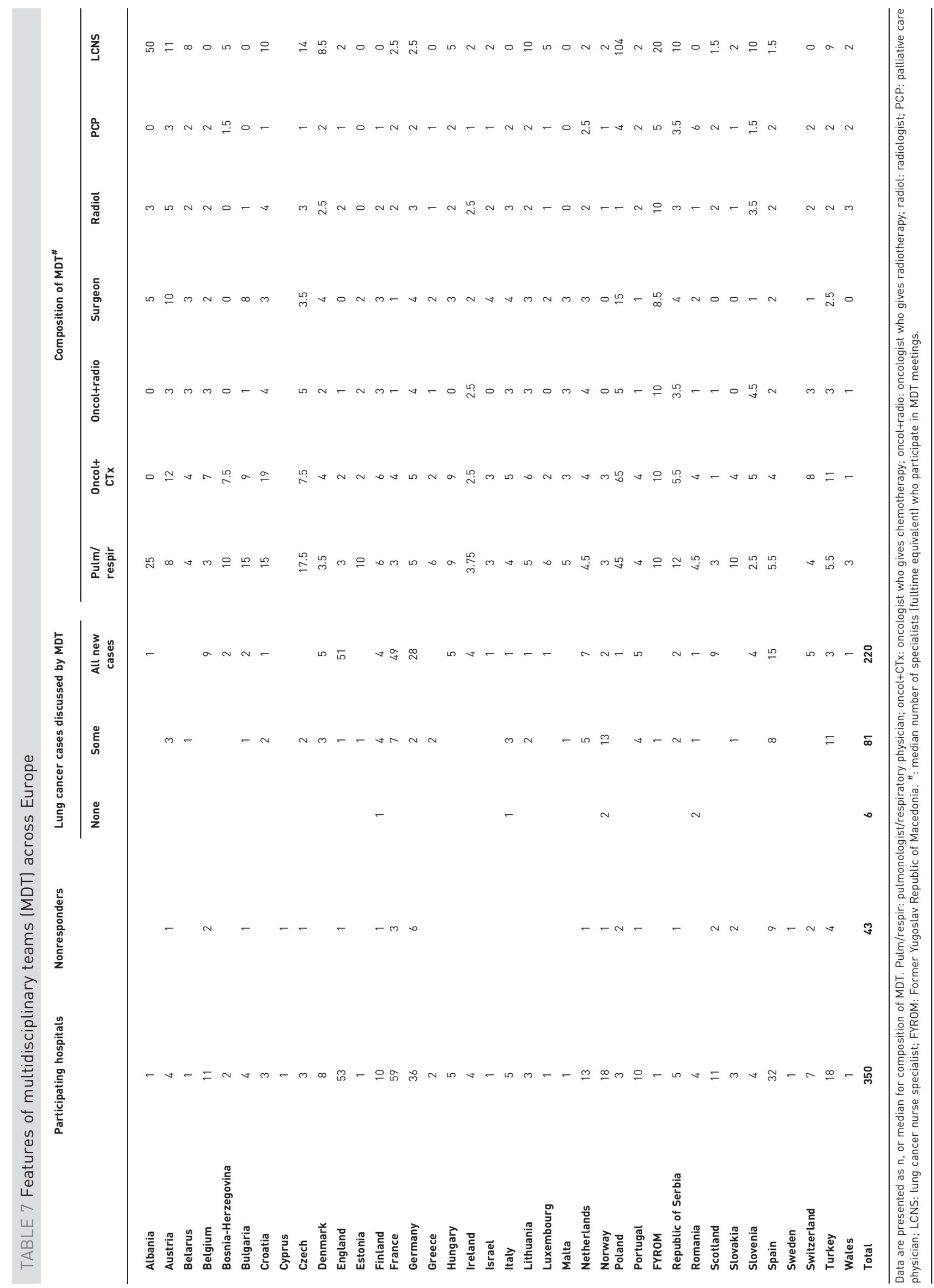




\section{Review of European lung cancer guidelines}

One of the key areas likely to influence quality is the use of guidelines to set standards of care. Quality might be influenced by the availability of a guideline, its content and whether a guideline, where available, is implemented or not. In turn, the latter may be influenced by the willingness to implement the guideline and by organisational, political and socioeconomic factors. Therefore, this project had two main objectives: 1) to create a database of all relevant guidelines in lung cancer that might be used in Europe; and 2) to assess the methodology used in producing these guidelines.

Methods

Identification of the guidelines

A Medline search was performed with the keywords listed online in Appendix 8. However, as guidelines are not necessarily published in scientific medical journals, other sources were explored, including: Guidelines International Network (www.g-i-n.net); NHS Evidence (www.evidence.nhs.uk); National Guidelines Clearinghouse (www.guideline.gov); SAGE Inventory of Cancer Guidelines (www.cancerguidelines.ca); the homepages of national and international societies; and personal contacts including ERS national delegates, Thoracic Oncology Assembly members and EIQMLCC members.

Guidelines were selected for review by one Task Force member (T. Blum). Those published between 2004 and 2011 whose principal scope was the diagnosis or management of lung cancer (anticancer treatment only) were included. Only the last update for each guideline was considered. Regional guidelines were only included when they were published in a peer-reviewed journal. The Google Translate tool (http://translate. google.com) was used to translate the text into English where necessary. These translations were checked within the group to ensure that the meaning was sufficiently preserved to allow assessment of the methodology used to produce the guideline.

\section{Assessment of guideline production methodology}

The Appraisal of Guidelines for Research and Evaluation (AGREE) II instrument was used to assess each guideline [72]. Each guideline was independently scored by four observers (T. Blum, J. Kollmeier, M.Paesmans and H. Sitter) except where observers were involved in the development of a guideline (P.M. Putora and T.E. Strand were substitutes). The six domains in AGREE II are: 1) scope and purpose (three items); 2) stakeholder involvement (three items); 3) rigor of development (eight items); 4) clarity of presentation (three items); 5) applicability (four items); and 6) editorial independence (two items).

Each item was rated on a 7-point scale. For each domain, a score (expressed as a percentage) was calculated based on the individual domain-specific item scores of the four observers, as recommended in the AGREE II manual. The higher the score, the better the methodological quality of the guideline for the corresponding AGREE II domain.

In addition, the following information was recorded: topic(s) covered; country; language and year of publication; the body that produced the guideline; whether the guideline was published in a scientific journal; and whether the guideline was intended to be used at a national or international level. Economic data for the country having issued the guideline was collected from the Organisation for Economic Cooperation and Development health statistics database [73]. This included percentage of gross domestic product that was dedicated to health expenditure and the absolute amount of health expenditure per capita. Data were taken for the year of guideline publication or, if not available, the current year. These figures were converted from US\$ to $€$ as per the conversion rate on November 24, 2012.

\section{Statistical analysis}

SAS version 9.2 (SAS Institute Inc., Cary, NC, USA) was used for statistical analyses. Characteristics of the guidelines and the AGREE II scores were analysed descriptively. Correlation between the domains was measured by calculating Pearson correlation coefficients. Analyses of variance (for categorical factors) or regression models (for continuous covariates) were used to assess the impact of guideline characteristics on the AGREE II scores. Univariate analyses selected factors with a p-value $<0.30$ for inclusion in the multivariate analyses. A p-value $<0.05$ was regarded as significant. As all analyses were exploratory, there was no adjustment for multiplicity.

\section{Results}

In total, 168 guidelines were found of which 87 were European. 56 guidelines fitted the inclusion criteria and were assessed by the four observers (Appendix 9 in supplementary material). Publication year ranged from 2004 to 2011 (the Ukrainian guideline had no date recorded), and 27 (48\%) guidelines were published (or updated) between 2010 and 2012. 13 (23\%) were produced by a multinational collaboration. The guidelines came from 25 countries and were written in 22 different languages. A governmental organisation 
was involved in $12(21 \%)$ guidelines and a scientific society in $41(73 \%) .25(45 \%)$ were published in a scientific journal. 26 guidelines were identified through Medline, 25 through guideline databases and 20 through homepages of national and international societies. Only 10 were identified through personal contacts. As expected, some guidelines focused on very specific areas, whilst others had a broad content (Appendix 10 in supplementary material). Only two guidelines would be recommended by the four observers without modification; a further 20 guidelines would be recommended with, or without, modification.

\section{Assessment of reported guideline production methodology}

The descriptive analysis of the six domain scores and the overall assessment are shown in table 8. The two domains that received the best score were scope and purpose (objectives and health questions target population) and clarity of presentation. The domains applicability of the guideline and editorial independence had the lowest scores. Rigour of development was strongly correlated with scope and purpose (Pearson correlation coefficient 0.86), involvement of stakeholders (0.85) and editorial independence (0.85). The lowest correlation was between clarity of presentation and applicability (0.44). All correlations were significantly different from the null hypothesis (all $\mathrm{p}<0.0001$ but clarity of presentation and applicability at $\mathrm{p}=0.001)$.

\section{Factors influencing the domain scores}

Table 9 shows the results of the univariate analyses of variance for the categorical variables. The scores for two domains, stakeholder involvement and applicability, were influenced by three factors: national guidelines for stakeholder involvement and international guidelines for applicability, those with involvement of a governmental body, and those published through other media than a medical journal had better scores. The involvement of a governmental body also had a positive influence on two other domains: scope and purpose and rigour of development. Finally, very recent guidelines were associated with independence from the funding bodies.

Multivariate analysis showed that for the domains scope and purpose, stakeholder involvement, rigour of development and clarity of presentation, the involvement of a governmental body and the involvement of a scientific society were associated with improved scores (table 10). For rigour of development the international nature of the guideline was associated with improved score $(\mathrm{p}<0.001)$. For applicability, publication in a medical journal was associated with lower scores $(\mathrm{p}<0.001)$, but involvement of a scientific society and publication after 2009 were associated with improved scores. For editorial independence, both the involvement of a scientific society $(\mathrm{p}<0.001)$ and publication during or after $2009(\mathrm{p}<0.01)$ were associated with a better score.

A strong correlation was observed between the two covariates that were measures of economic status (Pearson correlation coefficient $0.86, \mathrm{p}<0.0001$ ). After visual inspection of the data, the percentage of health expenditure of the gross domestic product was analysed as a continuous variable and the absolute amount of health expenses dichotomised according to the median that was $€ 2443$. Table 11 shows that for all domains, the countries that spend more on healthcare had significantly better scores $($ all $\mathrm{p}<0.05)$.

The involvement of a governmental body, involvement of a scientific society and publication year were all associated with more spending on healthcare.

Therefore, multivariate modelling was limited to health expenditure per capita, publication in a medical journal, broad content and comprehensive status. For only one domain, rigour of development, a broad content additionally impacted on the score with adjustment for the health expenditure.

TABLE 8 Appraisal of Guidelines for Research and Evaluation II scores by domain

\begin{tabular}{lcccc} 
Domain & Mean \pm SD $\%$ & $\mathbf{9 5 \%}$ Cl for the mean \% & Median \% & Min. \% \\
\hline D1 Scope and purpose & $47 \pm 18$ & $42-51$ & 47 & 11 \\
D2 Stakeholder involvement & $34 \pm 24$ & $28-40$ & 30 & 0 \\
D3 Rigour of development & $34 \pm 23$ & $28-40$ & 25 & 3 \\
D4 Clarity of presentation & $54 \pm 15$ & $50-58$ & 52 & 10 \\
D5 Applicability & $19 \pm 19$ & $14-24$ & 10 & 83 \\
D6 Editorial independence & $23 \pm 26$ & $16-30$ & 16 & 89 \\
Overall assessment & $43 \pm 20$ & $38-49$ & 42 & 80 \\
\hline
\end{tabular}




\section{TABLE 9 Analysis of variance for the six Appraisal of Guidelines for Research and Evaluation (AGREE) II domains}

\begin{tabular}{|c|c|c|c|c|c|c|c|}
\hline \multirow[t]{2}{*}{ Factor } & \multirow[t]{2}{*}{ Evaluated guidelines } & \multicolumn{6}{|c|}{ AGREE II domains } \\
\hline & & D1 & D2 & D3 & D4 & D5 & D6 \\
\hline \multicolumn{8}{|c|}{ Level of the guideline } \\
\hline International & $13(23)$ & 44 & 17 & 28 & 53 & 23 & 14 \\
\hline National & $43(77)$ & 47 & 39 & 36 & 54 & 6 & 26 \\
\hline$p$-value & & 0.61 & 0.003 & 0.25 & 0.91 & 0.004 & 0.15 \\
\hline \multicolumn{8}{|c|}{ Involvement of governmental body } \\
\hline Yes & $12(21)$ & 53 & 47 & 42 & 59 & 31 & 27 \\
\hline No & $44(79)$ & 45 & 30 & 32 & 52 & 16 & 22 \\
\hline $\mathrm{p}$-value & & 0.18 & 0.03 & 0.20 & 0.15 & 0.01 & 0.55 \\
\hline \multicolumn{8}{|c|}{ Involvement of a scientific society } \\
\hline Yes & $41(73)$ & 51 & 37 & 40 & 58 & 20 & 29 \\
\hline No & $15(27)$ & 33 & 27 & 18 & 43 & 16 & 8 \\
\hline $\mathrm{p}$-value & & 0.0006 & 0.19 & 0.0006 & 0.001 & 0.47 & 0.005 \\
\hline \multicolumn{8}{|c|}{ Publication in a medical journal } \\
\hline Yes & $25(45)$ & 43 & 23 & 28 & 54 & 9 & 19 \\
\hline No & $31(55)$ & 49 & 43 & 39 & 53 & 27 & 27 \\
\hline p-value & & 0.24 & 0.0007 & 0.06 & 0.89 & 0.0004 & 0.29 \\
\hline \multicolumn{8}{|l|}{ Broad content } \\
\hline Yes & $44(79)$ & 44 & 33 & 32 & 54 & 18 & 23 \\
\hline No & $12(21)$ & 55 & 36 & 44 & 52 & 23 & 25 \\
\hline p-value & & 0.09 & 0.76 & 0.09 & 0.68 & 0.45 & 0.77 \\
\hline \multicolumn{8}{|c|}{ Comprehensive guideline } \\
\hline Yes & $12(21)$ & 50 & 42 & 38 & 55 & 27 & 27 \\
\hline No & $44(79)$ & 46 & 32 & 33 & 53 & 17 & 22 \\
\hline p-value & & 0.53 & 0.17 & 0.58 & 0.74 & 0.10 & 0.57 \\
\hline \multicolumn{8}{|c|}{ Publication year" } \\
\hline Before 2010 & $29(53)$ & 46 & 29 & 32 & 52 & 15 & 17 \\
\hline $2010-2012$ & $26(47)$ & 47 & 39 & 37 & 55 & 24 & 30 \\
\hline$p$-value & & 0.72 & 0.14 & 0.48 & 0.49 & 0.11 & 0.05 \\
\hline
\end{tabular}

Data are presented as $\mathrm{n}$ (\%) or mean \%, unless otherwise stated. D1: scope and purpose; D2: stakeholder involvement; D3: rigour of development; D4: clarity of presentation; D5: applicability; D6: editorial independence. ${ }^{\#}$ : no date of publication for the Ukrainian guideline.

\section{Summary}

Although there are many guidelines that originate from Europe it was found that not all countries in Europe have guidelines. The quality of guidelines, as assessed by the AGREE II criteria, was found to be highly variable and average scores were low. Those guidelines achieving higher AGREE II scores were more likely to come from more affluent countries, which were also more likely to have involvement of governmental or scientific bodies in guideline development.

\section{The European Lung Cancer Audit}

Whilst the most desirable way to collect data for international comparison is via well organised and adequately funded cancer registries or national audits, the reality is that only a few countries have established the infrastructure necessary to support these. Therefore, to include the whole of Europe it is necessary to set up an international network that can collect a pre-specified dataset. Therefore, the aim of this project was to develop such a network and evaluate the feasibility of collecting prospective data on this scale.

\section{Methods}

Although an ambitious proposal, the Task Force agreed, as part of the original aims, to attempt prospective data collection from multiple European countries for a specified period. To achieve this, a national coordinator was nominated for each participating country whose role was to gain ethical approval, if required, and to engage and recruit colleagues in their country into the study. Several Task Force members took on this role, and for those countries not represented by the Task Force, national representatives who had participated in the national survey of infrastructure were invited. A core dataset was agreed by the Task Force and a patient consent form was developed, which was later translated by national coordinators where necessary. Data were collected prospectively as a feasibility study for the month of May 2012 (see exceptions below).

Web-based data entry tool

In order to allow prospective, "real-time" data collection, a secure web-based data entry tool was developed by $\mathrm{P}$. Beckett. To improve the security of the website, only those colleagues identified by the national 
TABLE 10 Results of multivariate analysis

\begin{tabular}{|c|c|c|c|c|c|c|}
\hline & D1 & D2 & D3 & D4 & D5 & D6 \\
\hline Scientific society & $<0.001$ & $<0.05$ & $<0.01$ & $<0.001$ & $<0.01$ & $<0.001$ \\
\hline $\begin{array}{l}\text { Governmental initiative } \\
\text { National/international }\end{array}$ & $<0.01$ & $<0.01$ & $\begin{array}{l}<0.05 \\
<0.001\end{array}$ & $<0.01$ & & \\
\hline $\begin{array}{l}\text { Publication in a medical journal } \\
\text { Comprehensive guideline }\end{array}$ & & & & & $<0.001$ & \\
\hline $\begin{array}{l}\text { Publication year } \\
\text { Broad content }\end{array}$ & & & & & $<0.01$ & $<0.01$ \\
\hline
\end{tabular}

Data are presented as p-values. D1: scope and purpose; D2: stakeholder involvement; D3: rigour of development; D4: clarity of presentation; D5: applicability; D6: editorial independence.

co-ordinator were issued with a location code, which was mandatory at the beginning of the data entry process. All data were anonymous and each new patient was allocated a unique identifier code.

Those countries with existing national registries or audit collection systems in place were invited to use these to transfer data and thereby avoid clinicians having to repeat data entry. Data upload in these countries does not always occur in "real-time" and so there is a lag time where data are uploaded and the validity checked. Clinicians in Denmark, England and Wales were encouraged (via emails) to enter data for the limited dataset, in a real-time manner for those patients diagnosed in May 2012. Data entry was closed on June 30, 2012 to allow data transfer and analysis. Scotland and the Netherlands were unable to transfer data from May 2012, and so it was agreed that they could share data on histologically and cytologically confirmed cases of lung cancer diagnosed in May 2011. Data from Germany were collected retrospectively at the regional level by clinical cancer registries.

A detailed description of the methodology can be found in the European Lung Cancer Audit study protocol (Appendix 11 in supplementary material).

\section{Results}

Several countries required ethical approval either at the national level on behalf of all centres, or locally for each separate participating centre (table 12). In some countries a fee was required by the ethics committee; this was met by a research grant from the Stiftung Oskar Helene Heim (Berlin, Germany).

26 countries uploaded data on a total of 2973 patients first diagnosed with lung cancer in May 2012. For the 23 countries without established audit programmes, data completeness (for each data item) was almost $100 \%$. There were between $5 \%$ and $8 \%$ of missing data for the components of stage, and $3 \%$ of patients had missing data for intended treatment. The number of patients entered per country ranged from four in Slovakia to 391 in Turkey. 18 of the 28 countries returning data submitted $>50$ patient records. The spread of histological subtypes was similar and the proportions of early and late stage cancers were similar for most

TABLE 11 Impact of the economic situation of the issuing country on the Appraisal of Guidelines for Research and Evaluation (AGREE) II domains

Factor

AGREE II domains

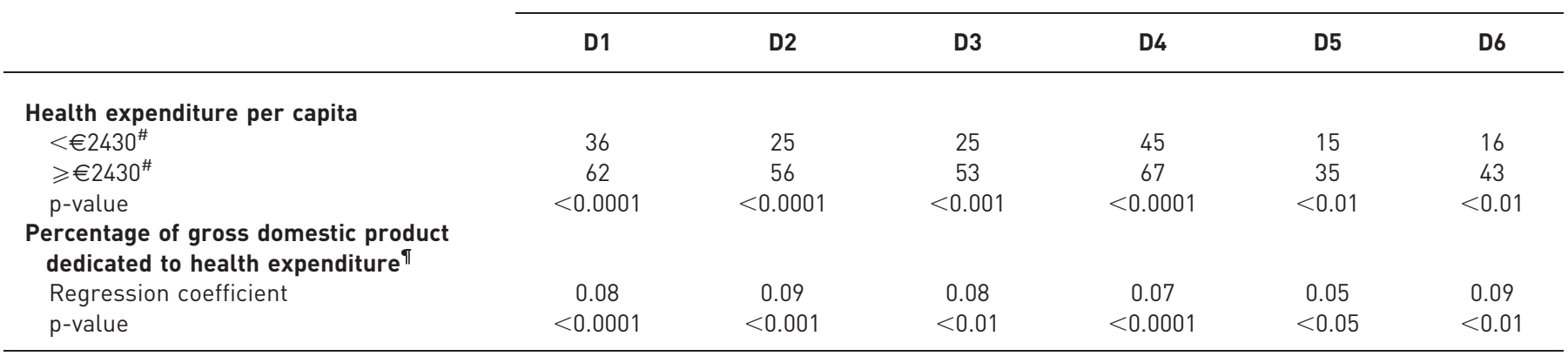

Data are presented as mean \%, unless otherwise stated. D1: scope and purpose; D2: stakeholder involvement; D3: rigour of development; D4: clarity of presentation; D5: applicability; D6: editorial independence. ${ }^{\#}: n=19 ;{ }^{\circledR}: n=36$. 
TABLE 12 Requirements for participation in the European Lung Cancer Audit study

\section{Ethical approval needed}

No ethical approval needed
No informed consent needed from every patient

$\begin{array}{cc}\text { Albania } & \text { Austria } \\ \text { Belgium" } & \text { Czech Republic } \\ \text { Bulgaria } & \text { Denmark } \\ \text { Croatia } & \text { England } \\ \text { Estonia } & \text { Ireland } \\ \text { Germany } & \text { Netherlands } \\ \text { Greece } & \text { Slovenia } \\ \text { Latvia } & \text { Scotland } \\ \text { Lithuania } & \text { Wales } \\ \text { Luxembourg } & \\ \text { Norway } & \\ \text { Poland } & \\ \text { Portugal } & \\ \text { Serbia } & \\ \text { Slovakia } & \\ \text { Spain } & \\ \text { Switzerland } & \\ \text { Turkey } & \\ \text { Ukraine } & \end{array}$

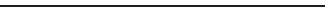

Albania
Belgium ${ }^{\#}$
Bulgaria
Germany
Greece
Lithuania
Norway
Portugal
Serbia
Spain
Switzerland
Turkey
Ukraine

\author{
Austria \\ Croatia \\ Czech Republic \\ Denmark \\ England \\ Estonia \\ Ireland \\ Latvia \\ Luxembourg \\ Netherlands \\ Poland \\ Slovakia \\ Slovenia \\ Scotland \\ Wales
}

\#: unable to participate as processing time of ethical approval was too long, except for one respondent.

countries with some exceptions. The results of the recorded data are presented in table 13. Data completeness for some of the established audits was less, for example for English data, only $70 \%$ of entries recorded performance status.

Data for Scotland were transferred on all patients diagnosed with lung cancer in May 2011. The Netherlands transferred a representative sample, approximately half of all those diagnosed in May 2011. Data transferred from Germany represent a sample of the 49 clinical cancer registries of Germany that document lung cancer care. These data were kindly provided by the Arbeitsgemeinschaft Deutscher Tumorzentren (Berlin, Germany). These results are presented in table 14.

\section{Summary}

This project has shown that it is feasible (organisationally) to collect a minimum clinical dataset from a large number of European countries by using a secure, anonymised, online tool. Not all countries that contributed to the surveys were able to participate in this clinical audit and those countries with established audit programmes appeared to have less complete data. There were some countries that were unable to participate due to difficulties in obtaining permission to share patient information. It is interesting to note that there are similarities in some data and marked differences in others. Some of this apparent variation could result from the extent to which the data were truly population-based as opposed to being institutional in origin. However, the purpose of this study was to demonstrate the feasibility of collecting data on this scale rather than ensuring accuracy.

\section{Discussion}

Despite improvements in diagnosis, staging and treatment, mortality remains high and survival remains low for those who develop lung cancer [3]. In contrast to knowledge of clinical research findings, little attention is given to findings involving quality improvement [6]. It has been shown that there are important differences in these outcome measures for some countries and that many lives would be saved were the best of the observed outcomes achieved in all countries [5]. In the UK there are now reliable data that can show differences in important aspects of lung cancer care and help drive changes that raise standards [56, 57]. There are a number of well-described methods of quality improvement and quality assurance in healthcare [74]. Research methods involve a variety of health service-based analyses and interventions designed to accumulate evidence or implement change whilst measuring the impact of that change $[75,76]$. These methods have only been applied in a limited number of countries and few applied on an international level. The EIQMLCC has applied selected quality improvement methodology to a large number of European 


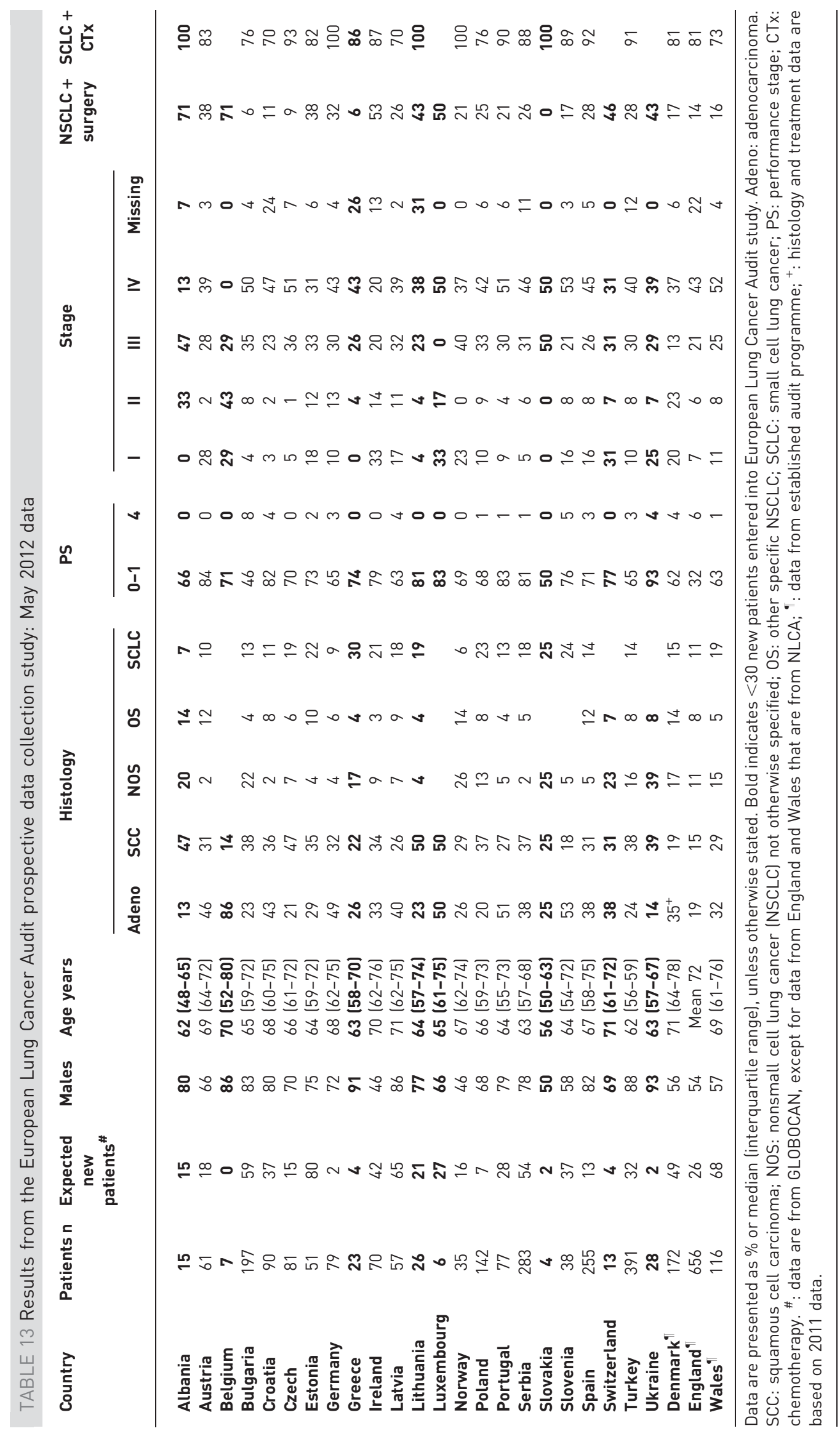


TABLE 14 Countries who contributed data from May 2011

\begin{tabular}{|c|c|c|c|c|c|c|c|c|c|c|c|c|c|c|c|c|c|c|}
\hline \multirow[t]{2}{*}{ Country } & \multirow{2}{*}{$\begin{array}{c}\text { Patients } \\
\text { n }\end{array}$} & \multirow{2}{*}{$\begin{array}{c}\text { Expected } \\
\text { new } \\
\text { patients }\end{array}$} & \multirow[t]{2}{*}{ Males } & \multirow{2}{*}{$\begin{array}{l}\text { Age } \\
\text { years }\end{array}$} & \multicolumn{5}{|c|}{ Histology } & \multicolumn{2}{|l|}{ PS } & \multicolumn{5}{|c|}{ Stage } & \multirow{2}{*}{$\begin{array}{l}\text { NSCLC + } \\
\text { surgery }\end{array}$} & \multirow{2}{*}{$\begin{array}{l}\text { SCLC } \\
+ \text { CTX }\end{array}$} \\
\hline & & & & & Adeno & SCC & NOS & OS & SCLC & $0-1$ & 4 & I & II & III & IV & Missing & & \\
\hline Germany & 1043 & 25 & 68 & $68(60-75)$ & 43 & 24 & 7 & 7 & 16 & 19 & 1 & 8 & 4 & 18 & 39 & 31 & 27 & 61 \\
\hline Netherlands & 432 & 48 & 64 & $67(61-75)$ & 39 & 26 & 6 & 14 & 16 & NA & & 13 & 6 & 23 & 54 & 4 & 68 & 70 \\
\hline Scotland & 270 & 73 & 55 & $70(64-76)$ & 26 & 32 & 12 & 5 & 26 & 58 & 2 & 7 & 6 & 29 & 48 & 10 & 13 & 70 \\
\hline
\end{tabular}

Data are presented as \% or median (interquartile range), unless otherwise stated. Adeno: adenocarcinoma. SCC: squamous cell carcinoma; NOS: nonsmall cell lung cancer (NSCLC) not otherwise specified; OS: other specific NSCLC; SCLC: small cell lung cancer; PS: performance stage; CTx: chemotherapy; NA: not available. " : data are from GLOBOCAN, except for data from Scotland that are from NLCA; ": data from established audit programme.

countries and has accumulated an unprecedented level of new information, including important insights into the limitations and challenges of quality improvement on this scale.

Using an extensive network of contacts, a detailed list of national and international European societies, charities and professional bodies has been compiled (Appendix 2 in supplementary material). The list illustrates just how many bodies there are that might play a role in the improvement of lung cancer outcomes. It is acknowledged that the list of societies and organisations is not comprehensive; however, many of the details ( 29 out of 41 countries) have been confirmed. For this to be a contemporary resource for development of pan-European initiatives it is essential that the list is corrected, augmented and updated on a regular basis, perhaps as a web-based solution and through nominated representatives.

\section{Review of the findings}

A detailed analysis of the existing published literature on all aspects of quality management in lung cancer care revealed a great many publications but few that were high quality when judged by traditional methods. Many studies examined single aspects of the care pathway and have suggested that improvements can be made (e.g. rapid access clinics) [23-26]. Others have suggested that certain institutional features can be associated with better outcomes (e.g. surgeon on site [50], surgical activity [57-62] and MDTs [30-35]).

National and local surveys were completed by more than 35 European countries. The data obtained illustrate important differences in the infrastructure of healthcare at the national and local (hospital) level. Knowledge of these factors is essential if strategies to improve quality of care are to be tailored to the requirements of individual countries. For many countries this was the first time they had contributed to this type of data collection and it enables them to see how their representative answers compare with other those of other countries.

The review of European lung cancer guidelines is, to the authors' knowledge, the most comprehensive systematic analysis of lung cancer guidelines. The 56 guidelines that were assessed differed widely in content and scope but at the same time there was duplication. Guideline development methodology was found to be highly variable across all domains of AGREE II. Multivariate statistical analyses showed that AGREE II scores were higher when guidelines were produced at an international level, where governmental or scientific bodies were involved and where the publication date was 2010 or after. Higher health spending was associated with better developed guidelines. These separate observations probably reflect the same fact that, within Europe, better resourced guideline development groups produce better guidelines.

The European Lung Cancer Audit project showed, for the first time in Europe, that it is entirely feasible to collect prospective demographic and clinical data on lung cancer patients in a pan-European setting. Although the results are interesting, they were not intended for detailed analyses as it was anticipated that there would be some difficulty in ensuring the questions meant the same to different nationalities. There were marked differences in treatment rates (surgical resection in nonsmall cell lung cancer and chemotherapy for small cell lung cancer). This may, in part, be due to the small numbers of patients submitted by some countries but is also likely to be due to the population denominator or the clinical focus of the centres participating in the survey. The population denominator is heavily influenced by the basis for inclusion of patients in a submitted dataset. 


\section{Strengths and weaknesses}

There are a number of proposed methods for quality improvement research that cover various aspects of the pathway to improved care. In comparison with a recently published classification of methods (epidemiology for health services research, organisational health services research, quality of life research, health economic evaluations and registries for health services research), our initiative has used three of these [7]. These were selected following discussions held by the Task Force.

The main limitation of the detailed literature review was that the search did not include studies published outside the PubMed literature, and only included articles written in English. This risked missing potential sources of information that would not normally be indexed, such as documents produced by governmental [77] and other influential bodies, or those written in non-English languages. Large documents may contain information on quality management within them, but if not listed as a key word will be missed by the search strategy; for example the ERS/European Society for Thoracic Surgeons fitness for radical therapy guidelines [78]. Another potential weakness is that the search and selection of articles was only conducted by one individual. However, the search and selection were performed according to published standards that ensure relevant literature is retained for review.

The principal limitation of the national and local surveys is that the data obtained may not be truly comparable between countries because of different interpretation of the questions or reliance on only a few individuals to submit data. In these preliminary data there did appear to be a link between number of surgeons, distance to travel for surgery and resection rates. Patients may exercise choices that are to their disadvantage when faced with difficulties in accessing healthcare. However, resection rate is heavily dependent on the population denominator and so these data must be interpreted with caution. It was discovered that some of the disparities were attributable to different healthcare systems; for example, those concerning composition of the MDT and others due to differences in the roles of professionals, e.g. lung cancer nurses. Despite these limitations, this work represents the first attempt to record the current practice of lung cancer care across Europe.

The review of lung cancer guidelines used robust published methodology to assess production quality (not content) and this was performed by four independent reviewers (minimum recommendation is two). The quality of translation, using Google, was found to be inadequate to assess guideline content but by using members of the Task Force to translate sufficiently accurate information was obtained to assess quality. It is also important to note that some guidelines did not report detailed methodology so a low score may not always reflect low quality.

The European Lung Cancer Audit feasibility study identified that, in some countries, the requirement of ethical approval and strict data security were barriers to the sharing of prospectively collected, anonymised data. Ensuring that the rights of individuals are not breached is important and so it is right that countries have mechanisms in place that protect against inappropriate use of data. The accuracy of these data has not been confirmed and therefore should not be used to compare clinical features and outcomes. This was not the aim of this project. EIQMLCC has built up a substantial network across Europe, with only a few larger countries not contributing data to the surveys or European Lung Cancer Audit. It is now important to maintain and extend this network by creating further projects that will contribute to improvements in lung cancer care.

\section{Future research in the context of EIQMLCC}

The list of professional societies, literature review and record of published guidelines are important resources for the future. A mechanism should be developed for them to be regularly updated. Further work and suggestions for future research are listed below.

1) The survey tools and information collected should be validated. Future work should be directed to clarifying questions, verifying the responses and designing further questions that examine other aspects of infrastructure. It is also important to examine whether these data can be used to link differences in infrastructure to differences in outcome.

2) Differences in guideline recommendations should be examined and the reasons established.

3) Research should be undertaken into the feasibility of producing a single European guideline that has recommendations that reflect the attainment of realistic standards of care within the limitations of the local healthcare system. If some of these recommendations are currently unachievable for some countries, development standards should be created to enable graded progression to the accepted gold standard.

4) The feasibility of creating a continuously updated record of references with a central international group to agree on interpretation of research findings in the context of guideline development should be 
considered. This would be efficient use of financial and human resources and allow each guideline to be developed to a high standard.

5) Research should be undertaken into the methods of guideline implementation including an analysis of the supportive and adjunctive material that is produced by some guideline groups [70]. This approach might be developed in the European setting in the future but would have to be supportive of local socioeconomic and political factors. This further work will be the basis for introducing a pan-European guideline development and implementation programme that in the future might be responsible for developing consensus guidelines that are the accepted standard throughout Europe.

6) The European Lung Cancer Audit project should be extended to collect an agreed minimum dataset out of existing datasets with clear data definitions but with modifications that reflect the international context. The ability to collect valid prospective data will be an invaluable tool to evaluate the effectiveness of quality improvement measures. It is important that the benefits to patients from analysing data at a European level are made clear. These data are vital to establish the inequalities in lung cancer care that exist and to measure the effect of interventions that improve outcomes and increase the standard of care.

\section{Conclusion}

Improving the quality of care for people on a European scale is a difficult and somewhat daunting task. Such a task requires a well organised administrative structure to manage it. Members of the Task Force have, therefore, proposed further research and development of an appropriately ambitious project whereby the ERS, in collaboration with other professional bodies, have begun developing a network for European lung cancer centres, steered by a committee composed of members of the ERS Thoracic Oncology Assembly. The group would have representation from all specialties and stakeholders in lung cancer care and subgroups would be responsible for several separate functions. The subgroups could include: 1) an evidence team, responsible for maintaining an up-to-date evidence base with consensus interpretation of evidence; 2) a guideline development team, responsible for evaluating guidelines and producing consensus statements; 3) an implementation team, responsible for putting guidelines into practice and identifying barriers to implementation; 4) a quality assurance team responsible for the pan-European collection of data from cancer registries and other sources; and 5) a study management team, responsible for facilitating research into areas where evidence is lacking.

With this structure in place the harmonisation of quality management of lung cancer care in Europe may provide an important lead for the same process in other respiratory diseases.

\section{Acknowledgements}

The author's affiliations are as follows. T.G. Blum: Klinik für Pneumologie, Lungenklinik Heckeshorn, HELIOS Klinikum Emil von Behring, Berlin, Germany. A. Rich: Dept Epidemiology and Public Health, Nottingham University Hospitals, Nottingham, UK. D. Baldwin: Dept of Respiratory Medicine, Nottingham University Hospitals, Nottingham, UK. P. Beckett: Burton Hospitals NHS Foundation Trust, Burton-on-Trent, UK. D. De Ruysscher: Radiation Oncology, University Hospitals Leuven/KU Leuven, Leuven, Belgium. C. Faivre-Finn: Christie NHS Foundation Trust, Manchester, UK. M. Gaga: $7^{\text {th }}$ Respiratory Medicine Dept, Athens Chest Hospital "Sotiria", Athens, Greece. F. Gamarra: Division of Respiratory Medicine and Thoracic Oncology and Thoracic Oncology Centre, Hospitals of the Ludwig-MaximiliansUniversity Munich, Munich, Germany. B. Grigoriu: Dept of Thoracic Oncology, Regional institute of Oncology, University of Medicine, Iasi, Romania. N.C.G. Hansen: Dept of Respiratory Medicine, Odense University Hospital, Odense, Denmark. R. Hubbard: Division of Respiratory Medicine, Nottingham University Hospitals, Nottingham, UK. R.M. Huber: Division of Respiratory Medicine and Thoracic Oncology and Thoracic Oncology Centre, Hospitals of the Ludwig-Maximilians-University Munich, Munich, Germany. E. Jakobsen: Dept of Thoracic Surgery, Odense University Hospital, Odense, Denmark. D. Jovanovic: University Hospital of Pulmonology, Clinical Centre of Serbia, Belgrade, Serbia. A. Konsoulova: Medical Oncology Clinic, University Hospital "Sveta Marina", Varna, Bulgaria. J. Kollmeier: Klinik für Pneumologie, Lungenklinik Heckeshorn, HELIOS Klinikum Emil von Behring, Berlin, Germany. G. Massard: Hôpitaux Universitaires de Strasbourg, Strasbourg, France. J. McPhelim: Cancer Division, Hairmyres Hospital, East Kilbride, UK. A-P. Meert: Dept of Oncological Intensive Care and Emergencies and Thoracic Oncology, Institut Jules Bordet, ULB, Brussels, Belgium. R. Milroy: Dept of Respiratory Medicine, Medical Block, Glasgow Royal Infirmary, Glasgow, UK. M. Paesmans: Data Center, Institut Jules Bordet, ULB, Brussels, Belgium. M. Peake: Dept of Respiratory Medicine, Glenfield Hospital, Leicester, UK. P-M. Putora: Dept of Radiation Oncology, Kantonsspital St. Gallen, Gallen, Switzerland. A. Scherpereel: Dept of Pulmonary and Thoracic Oncology, CHRU de Lille, Universite de Lille Nord de France, Lille, France. N. Schönfeld: Klinik für Pneumologie, Lungenklinik Heckeshorn, HELIOS Klinikum Emil von Behring, Berlin, Germany. H. Sitter: Institute of Surgical Research, Philipps-University Marburg, Marburg, Germany. K. Skaug: Dept of Medicine, Haugesund Hospital, Haugesund, and Institute of Medicine, University of Bergen, Bergen, Norway. S. Spiro: Dept of Thoracic Medicine, University College Hospital, London, UK. T-E. Strand: Cancer Registry of Norway, Oslo, Norway. S. Taright: Service Pneumologie, CHU Lamine Debaghine, Bab El Oued, Algeria. M. Thomas: Thoracic Oncology Clinic for Thoracic Diseases, University of Heidelberg, Heidelberg, Germany. P.E. van Schil: Dept of Thoracic and Vascular Surgery, Antwerp University Hospital, Antwerp, Belgium. J.F. Vansteenkiste: Dept Pneumology, Respiratory Oncology Unit, University Hospital Leuven/KU Leuven, Leuven, Belgium. R. Wiewrodt: Pulmonary Division, Dept of Medicine A, University Hospital, Westfaelische Wilhelms-University, Muenster, Germany. J-P. Sculier: Dept of Oncological Intensive Care and Emergencies and Thoracic Oncology, Institut Jules Bordet, ULB, Brussels, Belgium. 
The European Initiative for Quality Management in Lung Cancer Care would like to thank all those who participated in this project. We are very grateful to those who submitted data to the surveys and European Lung Cancer Audit project. We are also very grateful to the Stiftung Oskar Helene Heim (Berlin, Germany) for the research grant they provided to support the European Lung Cancer Audit feasibility study.

The national representatives from the European Initiative for Quality Management in Lung Cancer Care surveys are as follows. Albania: M. Nanushi; Austria: K. Kirchbacher; Belarus: A. Khorau and K. Uglanica; Belgium: L. Bosquee; BosniaHerzegovina: B. Mehic; Bulgaria: A. Konsoulova; Croatia: V. Ivcevic; Cyprus: M. Decatris; Czech Republic: J. Skrickova; Denmark: T.R. Rasmussen; Estonia: T. Laisaar; Finland: R. Makitaro; France: M. Wislez; Germany: T. Blum; Greece: A. Charpidou; Hungary: J. Moldvay; Iceland: S. Jonsson; Italy: S. Elia; Kyrgyzstan: M. Beishembaev; Lithuania: E. Danila; Luxembourg: M. Schlesser; Malta: S. Brincat; the Netherlands: S. Burgers; Norway: K. Skaug; Poland: J. DomagalaKulawik; Portugal: R. Sotto-Mayor; Romania: C. Paleru; Republic of Serbia: D. Jovanovic; Slovakia: P. Berzinec; Slovenia: N. Triller; Spain: I. Alfageme; Sweden: G. Hillerdal; Switzerland: L. Wannesson; Turkey: A. Erbaycu; Ukraine: N. Lukavetskyy; UK: M. Peake and R. Morgan.

The national coordinators for the European Lung Cancer Audit are as follows. Albania: M. Nanushi; Austria: O. Burghuber; Belgium: P. van Schil; Bosnia-Herzegovina: L. Burnazovic and B. Mehić; Bulgaria: A. Konsoulova; Croatia: M. Samarzija; Czech Republic: J. Skrikova; Denmark: E. Jakobsen; UK: M. Peake, R. Morgan, R. Milroy and N. McAndrew; Estonia: T. Laisaar; France: A. Scherpereel; Germany: R.M. Huber; Greece: M. Gaga; Iceland: S. Jonsson; Latvia: A. Krams; Lithuania: E. Danila; Luxembourg: M. Schlesser; Malta: S. Brincat; Moldova: A. Corlateanu; the Netherlands: R. Damhuis; Norway: T-E. Strand; Poland: J. Domagala-Kulawik; Portugal: R. Sotto-Mayor; Serbia: D. Jovanovic; Slovenia: T. Cufer; Spain: I. Alfageme; Switzerland: P-M. Putora; Turkey: T. Göksel; Ukraine: N. Lukavetskyy; Slovakia: E. Kavcová.

\section{References}

1 La Vecchia C, Bosetti C, Lucchini F, et al. Cancer mortality in Europe, 2000-2004, and an overview of trends since 1975. Ann Oncol 2010; 21: 1323-1360.

2 International Agency for Research on Cancer. GLOBOCAN 2008. www.globcan.iarc.fr Date last accessed: November 30, 2012.

3 Verdecchia A, Guzzinati S, Francisci S, et al. Survival trends in European cancer patients diagnosed from 1988 to 1999. Eur J Cancer 2009; 45: 1042-1066.

EUROCARE. Survival of cancer patients in Europe. www.eurocare.it Date last accessed: November 30, 2012.

5 Coleman MP, Forman D, Bryant H, et al. Cancer survival in Australia, Canada, Denmark, Norway, Sweden, and the UK, 1995-2007 (the International Cancer Benchmarking Partnership): an analysis of population-based cancer registry data. Lancet 2011; 377: 127-138.

6 Sculier JP, Vansteenkiste J, Schönfeld N, et al. Thoracic oncology in Europe: the ERS action plan by the Thoracic Oncology Assembly. Eur Respir J 2010; 36: 1227-1228.

7 Pfaff H, Glaeske G, Neugebauer EA, et al. Memorandum III: Methoden fur die Versorgungsforschung (Teil I) [Memorandum III: "Methods for Health Services Research" (Part 1)]. Gesundheitswesen 2009; 71: 505-510.

8 Ferlay J, Shin HR, Bray F, et al. GLOBOCAN 2008 v2.0: cancer incidence and mortality worldwide. In: IARC Cancer Base No.10. Lyon, International Agencty for Research on Cancer, 2010.

9 Holmberg L, Sandin F, Bray F, et al. National comparisons of lung cancer survival in England, Norway and Sweden 2001-2004: differences occur early in follow-up. Thorax 2010; 65: 436-441.

10 Peto R, Darby S, Deo H, et al. Smoking, smoking cessation, and lung cancer in the UK since 1950: combination of national statistics with two case-control studies. BMJ 2000; 321: 323-329.

11 Malvezzi M, Bertuccio P, Levi F, et al. European cancer mortality predictions for the year 2012. Ann Oncol 2012; 23: 1044-1052.

12 European Commission. Tobacco. Special Eurobarometer 332. Brussels, 2010.

13 Bogdanovica I, Godfrey F, McNeill A, et al. Smoking prevalence in the European Union: a comparison of national and transnational prevalence survey methods and results. Tob Control 2011; 20: e4.

14 European Commission. Council Recommendations on Smoke-Free Environments. Brussels, 2009.

15 Moher D, Liberati A, Tetzlaff J, et al. Preferred reporting items for systematic reviews and meta-analyses: the PRISMA statement. PLoS Med 2009; 6: e1000097.

16 Phillips B, Ball C, Sackett D, et al. Oxford Center for Evidence-based Medicine Levels of Evidence. www.cebm.net Date last updated: March 2009. Date last accessed: November 30, 2012.

17 von Meyenfeldt EM, Gooiker GA, van Gijn W, et al. The relationship between volume or surgeon specialty and outcome in the surgical treatment of lung cancer: a systematic review and meta-analysis. J Thorac Oncol 2012; 7: $1170-1178$.

18 Lee J, Marchbank A, Goldstraw P. Implementation of the British Thoracic Society recommendations for organising the care of patients with lung cancer: the surgeon's perspective. Ann R Coll Surg Engl 2002; 84: 304-308.

19 Lewis NR, Le Jeune I, Baldwin DR. Under utilisation of the 2-week wait initiative for lung cancer by primary care and its effect on the urgent referral pathway. Br J Cancer 2005; 93: 905-908.

20 Myrdal G, Lambe M, Hillerdal G, et al. Effect of delays on prognosis in patients with non-small cell lung cancer. Thorax 2004; 59: 45-49.

21 O’Rourke N, Edwards R. Lung cancer treatment waiting times and tumour growth. Clin Oncol (R Coll Radiol) 2000; 12: $141-144$

22 Salomaa ER, Sallinen S, Hiekkanen H, et al. Delays in the diagnosis and treatment of lung cancer. Chest 2005; 128: $2282-2288$.

23 Lal A, Phillips S, Russell C, et al. The novel use of fast track CT to select patients for lung cancer clinics: effect on clinic efficiency, waiting times, and patient satisfaction. Postgrad Med J 2011; 87: 264-268.

24 Prades J, Espinas JA, Font R, et al. Implementing a Cancer Fast-track Programme between primary and specialised care in Catalonia (Spain): a mixed methods study. Br J Cancer 2011; 105: 753-759.

25 Dunican E, Uzbeck M, Clince J, et al. Outcomes of patients presenting to a dedicated rapid access lung cancer clinic. Ir Med J 2011; 104: 265-268. 
Rajasekaran AB, Silvey D, Leung B, et al. Effect of a multidisciplinary lung investigation day on a rapid access lung cancer service. Postgrad Med J 2006; 82: 414-416.

27 Yilmaz A, Damadoglu E, Salturk C, et al. Delays in the diagnosis and treatment of primary lung cancer: are longer delays associated with advanced pathological stage? Ups J Med Sci 2008; 113: 287-296.

28 Mohammed N, Kestin LL, Grills IS, et al. Rapid disease progression with delay in treatment of non-small-cell lung cancer. Int J Radiat Oncol Biol Phys 2011; 79: 466-472.

29 Olsson JK, Schultz EM, Gould MK. Timeliness of care in patients with lung cancer: a systematic review. Thorax 2009; 64: 749-756.

30 von Plessen C, Aslaksen A. Improving the quality of palliative care for ambulatory patients with lung cancer. BMJ 2005; 330: 1309-1313.

31 Conron M, Phuah S, Steinfort D, et al. Analysis of multidisciplinary lung cancer practice. Intern Med J 2007; 37 : 18-25.

32 Whitaker NE, Stirling R, Naughton MT. Do multidisciplinary lung cancer clinics improve patient care? Intern Med J 2007; 37: 579-580.

33 Boxer MM, Vinod SK, Shafiq J, et al. Do multidisciplinary team meetings make a difference in the management of lung cancer? Cancer 2011; 117: 5112-5120.

34 Coory M, Gkolia P, Yang IA, et al. Systematic review of multidisciplinary teams in the management of lung cancer. Lung Cancer 2008; 60: 14-21.

35 Bydder S, Hasani A, Broderick C, et al. Lung cancer multidisciplinary team meetings: a survey of participants at a national conference. J Med Imaging Radiat Oncol 2010; 54: 146-151.

36 Bydder S, Nowak A, Marion K, et al. The impact of case discussion at a multidisciplinary team meeting on the treatment and survival of patients with inoperable non-small cell lung cancer. Intern J Med J 2009; 39: 838-841.

37 Boxer MM, Vinod SK, Shafiq J, et al. Do multidisciplinary team meetings make a difference in the management of lung cancer? Cancer 2011; 117: 5112-5120.

38 Freeman RK, Van Woerkom JM, Vyverberg A, et al. The effect of a multidisciplinary thoracic malignancy conference on the treatment of patients with lung cancer. Eur J Cardiothorac Surg 2010; 38: 1-5.

39 Martin-Ucar AE, Waller DA, Atkins JL, et al. The beneficial effects of specialist thoracic surgery on the resection rate for non-small-cell lung cancer. Lung Cancer 2004; 46: 227-232.

40 Forrest LM, McMillan DC, McArdle CS, et al. An evaluation of the impact of a multidisciplinary team, in a single centre, on treatment and survival in patients with inoperable non-small-cell lung cancer. Br J Cancer 2005; 93: 977-978.

41 Gaertner J, Wolf J, Scheicht D, et al. Implementing WHO recommendations for palliative care into routine lung cancer therapy: a feasibility project. J Palliat Med 2010; 13: 727-732.

42 de Sa E, Sinclair E, Mitera G, et al. Continued success of the rapid response radiotherapy program: a review of 2004-2008. Support Care Cancer 2009; 17: 757-762.

43 Bowen EF, Anderson JR, Roddie ME. Improving surgical resection rates in lung cancer without a two stop service. Thorax 2003; 58: 368.

44 Salati M, Brunelli A, Dahan M, et al. Task-independent metrics to assess the data quality of medical registries using the European Society of Thoracic Surgeons (ESTS) Database. Eur J Cardiothorac Surg 2011; 40: 91-98.

45 Schwarzbach M, Rossner E, Schattenberg T, et al. Effects of a clinical pathway of pulmonary lobectomy and bilobectomy on quality and cost of care. Langenbecks Arch Surg 2010; 395: 1139-1146.

46 Aveling EL, Martin G, Jimenez Garcia S, et al. Reciprocal peer review for quality improvement: an ethnographic case study of the Improving Lung Cancer Outcomes Project. BMJ Qual Saf 2012; 21: 1034-1041.

47 Birkmeyer JD, Stukel TA, Siewers AE, et al. Surgeon volume and operative mortality in the United States. $N$ Engl J Med 2003; 349: 2117-2127.

48 Birkmeyer JD, Sun Y, Goldfaden A, et al. Volume and process of care in high-risk cancer surgery. Cancer 2006; 106: $2476-2481$.

49 Finlayson EV, Goodney PP, Birkmeyer JD. Hospital volume and operative mortality in cancer surgery: a national study. Arch Surg 2003; 138: 721-725.

50 Goodney PP, Lucas FL, Stukel TA, et al. Surgeon specialty and operative mortality with lung resection. Ann Surg 2005; 241: 179-184.

51 Hannan EL, Radzyner M, Rubin D, et al. The influence of hospital and surgeon volume on in-hospital mortality for colectomy, gastrectomy, and lung lobectomy in patients with cancer. Surgery 2002; 131: 6-15.

52 Lien YC, Huang MT, Lin HC. Association between surgeon and hospital volume and in-hospital fatalities after lung cancer resections: the experience of an Asian country. Ann Thorac Surg 2007; 83: 1837-1843.

53 Yasunaga H, Hashimoto H, Horiguchi $\mathrm{H}$, et al. Variation in cancer surgical outcomes associated with physician and nurse staffing: a retrospective observational study using the Japanese Diagnosis Procedure Combination Database. BMC Health Serv Res 2012; 12: 129.

54 Lee JS, Scott CB, Komaki R, et al. Impact of institutional experience on survival outcome of patients undergoing combined chemoradiation therapy for inoperable non-small-cell lung cancer. Int J Radiat Oncol Biol Phys 2002; 52: 362-370.

55 Rich AL, Tata LJ, Stanley RA, et al. Lung cancer in England: information from the National Lung Cancer Audit (LUCADA). Lung Cancer 2011; 72: 16-22.

56 Rich AL, Tata LJ, Free CM, et al. Inequalities in outcomes for non-small cell lung cancer: the influence of clinical characteristics and features of the local lung cancer service. Thorax 2011; 66: 1078-1084.

57 Rich AL, Tata LJ, Free CM, et al. How do patient and hospital features influence outcomes in small-cell lung cancer in England? Br J Cancer 2011; 105: 746-752.

58 Strand TE, Bartnes K, Rostad H. National trends in lung cancer surgery. Eur J Cardiothorac Surg 2012; 42: 355-358.

59 Strand TE, Rostad H, Damhuis RA, et al. Risk factors for 30-day mortality after resection of lung cancer and prediction of their magnitude. Thorax 2007; 62: 991-997.

60 Strand TE, Brunsvig PF, Johannessen DC, et al. Potentially curative radiotherapy for non-small-cell lung cancer in Norway: a population-based study of survival. Int J Radiat Oncol Biol Phys 2011; 80: 133-141.

61 von Plessen C, Strand TE, Wentzel-Larsen T, et al. Effectiveness of third-generation chemotherapy on the survival of patients with advanced non-small cell lung cancer in Norway: a national study. Thorax 2008; 63: 866-871. 
62 De Geer A, Eriksson J, Finnern HW. A cross-country review of data collected on non-small cell lung cancer (NSCLC) patients in cancer registries, databases, retrospective and non-randomized prospective studies. J Med Econ 2013; 16: 134-149.

63 Langer CJ, Moughan J, Movsas B, et al. Patterns of care survey (PCS) in lung cancer: how well does current U.S. practice with chemotherapy in the non-metastatic setting follow the literature? Lung Cancer 2005; 48: 93-102.

64 Jakobsen E, Palshof T, Osterlind K, et al. Data from a national lung cancer registry contributes to improve outcome and quality of surgery: Danish results. Eur J Cardiothorac Surg 2009; 35: 348-352.

65 Mainz J, Hansen AM, Palshof T, et al. National quality measurement using clinical indicators: the Danish National Indicator Project. J Surg Oncol 2009; 99: 500-504.

66 Hermens RP, Ouwens MM, Vonk-Okhuijsen SY, et al. Development of quality indicators for diagnosis and treatment of patients with non-small cell lung cancer: a first step toward implementing a multidisciplinary, evidence-based guideline. Lung Cancer 2006; 54: 117-124.

67 Goeckenjan G, Sitter H, Thomas M, et al. Prevention, diagnosis, therapy, and follow-up of lung cancer: interdisciplinary guideline of the German Respiratory Society and the German Cancer Society. Pneumologie 2011; 65: 39-59.

68 Lennes IT, Lynch TJ. Quality indicators in cancer care: development and implementation for improved health outcomes in non-small-cell lung cancer. Clin Lung Cancer 2009; 10: 341-346.

69 Tanvetyanon T. Quality-of-care indicators for non-small cell lung cancer. Cancer Control 2009; 16: 335-341.

70 Braun V, Clarke V. Using thematic analysis in psychology. Qual Res Psychol 2006; 3: 77-101.

71 National Institute for Health and Care Excellence. The diagnosis and treatment of lung cancer (update). Full guideline. Appendix 1: Needs assessment questionnaire sent to LHB'S IN Wales and lung cancer leads in England. www.nice.org.uk Date last updated: April 2011. Date last accessed: November 30, 2012.

72 Brouwers M, Kho ME, Browman GP, et al. AGREE II: advancing guideline development, reporting and evaluation in healthcare. Can Med Assoc J 2010; 182: E839-E842.

73 Organisation for Economic Cooperation and Development. Data visulisation for key OECD data. www.oecd.org Date last accessed: November 30, 2012.

74 The Health Foundation. Quality Improvement Made Simple. 2nd Edn. London, Health Foundation, 2013.

75 Greenhalgh T, Russell J, Swinglehurst D. Narrative methods in quality improvement research. Qual Saf Health Care 2005; 14: 443-449.

76 Grol R, Baker R, Moss F. Quality improvement research: understanding the science of change in healthcare. Qual Saf Health Care 2004; 12: 538-539.

77 Health and Social Care Information Centre. National Lung Cancer Audit Report 2011. www.hscic.gov.uk Date last accessed: November 30, 2012.

78 Brunelli A, Charloux A, Bolliger CT, et al. ERS/ESTS clinical guidelines on fitness for radical therapy in lung cancer patients (surgery and chemo-radiotherapy). Eur Respir J 2009; 34: 17-41. 